\title{
4 Routes: Understanding Mobility
}

'I have come to think of this additional geographic dimension of socioeconomic class in terms of two groups that I refer to simply as the mobile and the rooted. The mobile possess the means, resources, and inclination to seek out and move to locations where they can leverage their talents. They are not necessarily born mobile, nor are they inevitably rich. What the mobile understand is that pursuit of economic opportunity often requires them to move. [...] A far greater number constitute the rooted-people who are tied to place.'

Richard Florida (2008: 79-80)

As Richard Florida's statement highlights, there is a group of people who live a more mobile life than the rest of the population. We thus have to think about what mobility means in contemporary society. This chapter will be dedicated to the study of mobility as it is discussed in current sociological and geographical analyses. I will focus on two promising notions that I find relevant to my study. First, the idea of an upcoming transnationalism is helpful as it allows us to understand how lifeworlds of people do not fit into and do not relate to only a single nation-state. The social space in which people live today is increasingly going beyond national boundaries and transgressing the former restrictions that come along with these boundaries. Second, the concept of multilocality is taking a similar perspective, yet on a smaller geographic scale: namely the local scale instead of the national one. Multilocality research has emerged in the social sciences of the German speaking world (Germany, Switzerland and Austria) in order to understand how people who circulate between different places on a regular basis relate to this circulation and to the places involved.

\subsection{Transnationalism}

Since the early 1990s, the notion of transnationalism spread in social sciences. Studies that deal with the lifeworlds of people living 'in-between' two or more nationstates increasingly refer to this term (Brickell \& Datta, 2011a). In particular, migration scholars have adopted the concept in order to understand the new forms of circular migration that have occurred in the frame of increasing integration of global (labour) markets. Principally, transnationalism is about the various linkages that mobile individuals develop to different nation-states and national societies. The pioneers of current transnationalism research, Glick Schiller et al. (1992: 1f.), defined transnationalism as 'the processes by which immigrants build social fields that link together their country of origin and their country of settlement. Immigrants who build such social fields are designated 'transmigrants'. Transmigrants develop and maintain multiple relations - familial, economic, social, organizational, religious, and political that span borders. Transmigrants take actions, make decisions, and feel concerns, and 
develop identities within social networks that connect them to two or more societies simultaneously'.

Glick Schiller et al. (1992) studied migrant groups from the Philippines and several Caribbean Islands in New York. They found that the transnationalism concept is subject to six premises. First, existing sociological categories such as nation, ethnic group, culture and society no longer suffice to grasp circular forms of migration between nation-states, and they help little in the study of transnationalism. Second, changing migration patterns are strongly interwoven with the extension of global capitalism and the worldwide integration of markets. The spatial reorganization of production as well as the increased dynamic of relocations has made migrant workers a more vulnerable group. Their response could be seen in the transnationalisation strategy, which Glick Schiller et al. (1992) understand as a form of risk distribution. Third, transnationalism must be understood as grounded in the daily lives, activities and social relations of migrants. Fourth, these transnational migrants are forced to confront, draw upon, and rework different national, ethnic and racial identity constructs. Fifth, sociological concepts have to be reconceptualised, primarily class, culture, society, nation, ethnicity and race. Here, Glick Schiller et al. (1992) criticise the approaches developed in the field of cultural studies (e.g. Hannerz's [1990] idea of an opposition between cultural homogenisation and cultural creolisation) for underestimating the migrants' capacity to mediate between existing cultures. Sixth, while transnational migrants are constrained by national hegemonic contexts, they also actively reshape these contexts through their practices.

Furthermore, transnational situations do not only occur in migrational contexts. They can also exist in the everyday life of physically immobile persons. The migration scholar Ludger Pries thus prefers to differentiate between three different social scales instead of between spatial mobility (migration) and spatial immobility (no migration). According to Pries (2008), transnationalism is the conscious and opportune connecting of two or more national backgrounds (referring to nation-states, national legislation, national culture, national language etc.) by private individuals (micro level), by economic corporations and non-governmental organizations (meso level), and by state actors (macro level). Other than in more traditional approaches of internationalism/internationalisation, the interaction between national governments only plays a minor role in transnationalism. Actors at the micro and meso level who 'transcend' nation-states' boundaries represent the focus of attention.

Pries also wants to avoid using 'transnational' to label everything that crosses borders. So, he applies the term only to phenomena of social change that cannot be studied in the frame of 'methodological nationalism' (cf. discussion as raised by Beck \& Grande, 2010²3). Pries says (2010: $\left.10^{24}\right)$ : 'Transnationalism in the narrow sense looks

23 Beck \& Grande criticise social and political theory and methodology for referring only to national frames. They say (2010: 412): 'Until recently, social theory has taken the nation-state as its implicit unit 
for the social phenomena and social relations which are spanning different local units in different national societies, and which are relatively stable and include comparably dense interaction.' Pries later adds (2010: 1325): 'The terms transnational and transnationalisation are understood here as cross-border phenomena, which - still rooted locally and in different national societies - constitute relatively enduring and tight social relations, social networks or social spaces.'

He also speaks of an equal distribution of activities to the involved places. Frequency and density of social relations are the central criteria for making transnationalism a new phenomenon and for counteracting criticism on the part of historians who tend to argue that transnationalism has always existed and is nothing new. For Pries, the early mobility of people was characterised by a rather monolocal territorialisation of the lifeworld. This is no longer the case in contemporary forms of transnational territorialisation. In this context, Itzigsohn et al. (1999; cited in Schmiz, 2011: 21) introduced a differentiation of transnational migration according to the migrants' degree of involvement into transnational social spaces. Studying Dominican transnational migrants, they found that there is a continuum between 'narrow' and 'broad' transnationalism. Itzigsohn et al. used three dimensions to measure the involvement: frequency of trips between countries; institutionalisation of a person (meaning the formality of membership in organizations); and involvement of a person (meaning the frequency of participation in collective agency). If transnational migrants score high in these dimensions, they are part of a narrow transnationalism. By contrast, if they seldom travel, or are not institutionalised or personally involved, they might be considered representatives of broad transnationalism. Additionally, Itzigsohn et al. (1999: 324) presented four dimensions of transnationality: 1) economic; 2) political; 3) civil societal; and 4) cultural. One could then study the quality of transnational ties according to these dimensions.

According to Pries, transnationalism - in contrast to what many globalization scholars believe - does not expect a declining relevance of national borders and

of analysis; the terms 'society' and 'culture' implicitly referred to what have been perceived as discrete, self-contained and relatively homogenous entities bounded by national borders, institutions and legal frameworks. Accordingly, theory has operated with an unquestioned assumption of a neat correspondence between nation, territory, society and culture.' As a consequence they argue for a 'methodological cosmopolitanism'. This view is also shared by some scholars of transnationalism such as Wimmer \& Glick Schiller (2002).

24 Translated by the author from the German text: 'Der Transnationalismus im hier verstandenen engeren Sinne dagegen betrachtet vor allem solche Sozialphänomene und sozialen Beziehungen, die sich über mehrere lokale Einheiten in unterschiedlichen Nationalgesellschaften hinaus erstrecken, die relativ dauerhaft sind und vergleichsweise dichte Interaktionen beinhalten.'

25 Translated by the author from the German text: 'Mit den Begriffen transnational und Transnationalisierung werden hier grenzüberschreitende Phänomene verstanden, die - lokal verankert in verschiedenen Nationalgesellschaften - relativ dauerhafte und dichte soziale Beziehungen, soziale Netzwerke oder Sozialräume konstituieren.' 
nation-states. Nation-states and all aspects of the lifeworld that are based on national regulation maintain their power in defining a person's life. There is no straightforward deterritorialisation. Pries (2009) instead argues that different locales are combined within one lifeworld across remaining national borders. Transnationalism studies focus on new forms of socialisation (soziale Vergemeinschaftung). Consequently one could understand globalization as the sum of all transnational ties in the world. Pries thinks of transnationalism as one ideal type of the internationalisation of 'socialisation' (which he here calls Vergesellschaftung). He distinguishes transnationalisation from six other ideal types (Pries, 2009: 592-595). Four out of these ideal types of the 'internationalisation of socialisation' might still be studied applying the assumptions of 'methodological nationalism' (mainly the assumed superposition of geographic and social space on the national scale): 1) internationalisation as the process of intensifying relationships between nation-states; 2) renationalisation as the answer to internationalisation and globalisation by closing one's own borders and reconcentrating on one's own nation-states' internal socio-cultural life; 3) supra-nationalisation, which is the opposite answer to renationalisation, including an upgrading of sovereignty to a geographic scale above the nation-state but below the global scale; 4) globalisation as the process through which internationalised relationships between nation-states increasingly take place globally and not only within limited world regions. The superposition of social and geographic space must not necessarily be questioned in order to study these processes. According to Pries (2009), the only and minor criticism stems from those scholars who argue for a diminishing relevance of geographic/physical space for socialisation (the 'virtualisation argument' as e.g. to be found in John Urry's 'mobilities' (2000) and Manuel Castells' 'spaces of flows' (2000b)).

On the other hand, there are also processes of internationalisation of socialisation which call attention to geographic space, but which cannot be studied using methodological nationalism (cf. Pries, 2009: 594f.): 5) glocalisation, which is a circumscription for the dialectic between the global and the local scale, including processes of new bordering and reterritorialisation; 6) the spread of diaspora situations, which include the fact that one social space can be spread to very different geographic spaces across national borders and with an orientation to a shared homeland; 7) transnationalisation, which represents the emergence of new 'transand pluri-local configurations' above and beyond nation-states. Thus, it becomes clear that there is a set of different processes happening at the same time that might be confounded with transnationalisation. However, as Pries has presented, they have a different character and need differentiated epistemological approaches. Transnationalism consists of the social practice of combining different national contexts and their opportunities. Therefore transnationalism should be studied with critical distance to methodological nationalism (cf. Glick Schiller et al., 1997; Pries, 1997). 
Interestingly, Pries also argues that transnationalism can only exist as long as the nation as an anchor point or 'reference' is available (2010: $\left.12^{26}\right)$ : '[It] is only possible to speak of transnationality or transnationalisation if and as long as nations, nation-states and national societies still exist - the transnational as something exceeding the nations can only exist as long as there are nations as reference points for the denotative.'

Transnationalism as a field for studying current phenomena of cross-border mobility thus also takes into consideration that mobility (here cross-border migration) and place (here the nation understood as materialising in the local) are strongly interrelated.

\subsubsection{Transnational Social Spaces and Transnational Social Fields}

Pries started to study Mexican family networks in which some of the family members were living (at least temporarily) in the United States. Even though his research starts from the observation of migrational movements, Pries also derived more general conclusions about transnationalism. Pries (2008) observes that the former unity of 'geographic space' and 'social space' - as found in the modern nation-state with an accompanying national society - is being disrupted more and more. The nation-state is still an important frame of reference for social life in postmodern societies, but social interaction also takes place by 'transcending' the nation-state's boundaries. The social interaction on the level of individual lifeworlds is evermore taking place across borders, and thus in a more or less 'transnational' way. This means that we have to think of social space and its relation to geographic space in a new way (cf. Pries, 2010).

To approach the term 'space', Pries (1997: 17) draws back on Simmel's (1903) 'Soziologie des Raumes' (sociology of space). Simmel described three main properties of social space. First, there are different types of social formations. Some social formations are geographically exclusive. This means that one social formation does not accept another similar social formation in the same territory (e.g. where one nationstate is, there is no other). On the other hand, there are social formations that can co-exist in geographic space (e.g. different religious groups in the same city). Second, Simmel thinks of social space as something that has a border delimiting it from other social spaces. Built up for distinction, this border consequently leads to geographic borders. This idea includes the logic that a border is not a geographic fact with a social impact but vice versa: a geographic outcome of social practice and discourse

26 Translated by the author from the German text: '[Es] kann von Transnationalität oder Transnationalisierung nur solange und dann die Rede sein, wenn (noch) Nationen, Nationalstaaten und Nationalgesellschaften bestehen - Transnationales als Nationen überschreitendes bzw. übergreifendes kann nur solange existieren, wie es Nationen als Bezugspunkte des zu Bezeichnenden gibt.' 
(Pries, 1997: 17). Third, Simmel observed that geographic space allows social space to materialise (in a location) and concentrate (density of social interaction). Pries comments that in sociology such a concept of social space persisted for a long time, including the superposition of geographic space (national territory) and social space (national society and culture). This superposition was only questioned upon the arrival of Luhmann's Systemtheorie, because Luhmann thought of societies as consisting of communication. Consequently society had to be looked at on a global scale, not a national one, because communication does not stop at national borders (Pries, 1997: 17).

Pries therefore suggests conceptualising geographic space not as a container (e.g. like a national territory) but as a relational space in which objects are located and related to each other. Social space should then be thought of as characterised by lifestyles and the different forms of cultural, social, economic and symbolic capital (as derived from Bourdieu). In sum, an individual lives in their own 'action space', which has a geographic and a social dimension. Here, Pries draws back on the work of Hägerstrand (1970) and Giddens (1985). In particular, Pries makes use of Giddens' concepts of 'locales' and 'regions'. According to Giddens, 'locales' are the specific socio-spatial settings in which everyday social interaction takes place, and 'regions' defines a specific 'zoning of time-space' that an individual navigates in everyday life (Giddens, 1985: 271f.; cited in Pries, 1997: 28). Pries applies Giddens' ideas to the specific topic of transnationalism and speaks of 'transnational social space'. Transnational social spaces represent the emancipation of social space from geographic space. Pries says (1997: $34^{27}$ ): 'We suggested understanding transnational social spaces as new spaces of social relations (Elias, 1986: 'soziale Verflechtungsräume'), which are diffuse in terms of geographic space as well as multilocal, and which constitute at the same time not only a transitory social space. This social space is an important reference structure for social positions and positioning, and it defines everyday life practices, (professional) biographic projects and identities of the people. Furthermore, it indicates the existence of social relationship beyond the limits of national societies (Pries et al., 1995; Pries, 1996).' Transnational social spaces thus call for a concrete social interaction between people, and this mostly involves that people are physically mobile across borders. Yet, these spaces have an imaginative and virtual dimension, too. Pries even calls them 'imaginative or virtual places' (1997: 24).

27 Translated by the author from the German original: 'Wir haben vorgeschlagen, Transnationale Soziale Räume als neue „soziale Verflechtungsräume“ (Elias 1986) zu verstehen, die geographisch-räumlich diffus bzw. multi-lokal sind und gleichzeitig einen nicht nur transitorischen sozialen Raum konstituieren, der sowohl eine wichtige Referenzstruktur sozialer Positionen und Positionierungen ist, als auch die alltagsweltliche Lebenspraxis, (erwerbs-) biographischen Projekte und Identitäten der Menschen bestimmt und zugleich über den Sozialzusammenhang von Nationalgesellschaften hinausweist (Pries et al.1995 und Pries 1996).' 
Schmiz (2011: 22f.) adds that transnational social spaces are always linked to different geographic spaces as they include different locales in different nation-states. However, a transnational social space is defined by an equal distribution of activities and importance across all involved places. This means that social interaction and ties are dense and stable in time. Furthermore, it is not possible to define a dominant geographic centre within a transnational social space. Schmiz also explains that transnational social spaces are 'imagined' spaces that come into awareness only after concrete transnational social interaction. Thus, the extension of transnational social spaces has to be thought of as something individual and subjective.

Bommes (2002) appreciates the emergence of the concept of 'transnational social space'. According to him, transnationalism can be understood as the disintegration of society from the nation-state. But if one disintegrates society from the nation-state, one has to reintegrate it somewhere else. Bommes thinks of 'transnational social spaces' as exactly such a solution for the reintegration of the society. Only through this are sociological studies of migration phenomena possible. Yet, Bommes also lists six critical points, which follow from his conviction that the concept of transnational social space is still insufficient (Bommes, 2002: 94-98). First, transnationalism rejects the national as the dominant geographic scale. At the same time, the concept of transnational social space draws on the category of 'space', and by doing so it uses 'space' again to redraw new borders that still rely on territoriality. Second, the use of 'space' as a category is misplaced as it is one of the main irreducible dimensions of sociology (next to time or society), and as such 'transnational social spaces' are delimited in 'spatial' terms. Third, the concept does not suffice to replace the 'national society as container' idea, because it represents a container in itself. In terms of structural theory it does not help much to better understand society, as Bommes (2002) argues. Fourth, it is unclear to what degree transnationalism will remain its own paradigm or only a temporary experience of criticism against nationalism. Fifth, Bommes highlights that nation-states still structure opportunities through setting legal frames. Therefore, transnational social spaces cannot become an independent space as they are dependent on the existence of the nation-state. Sixth, the central role of the 'network' as a structural pattern of transnational social spaces is problematic. Networks are seldom operationalised in transnationalism studies. Transnationalism scholars often use this term without explaining which structure they are analyzing and referring to, and how these structures come into being. To sum up, Bommes (2002) mentions that transnationalism and transnational social space are concepts that have developed without reference to social theory. Whereas he positively evaluates Vertovec's (2001) idea of a 'transnational social formation', he would prefer to include the 'theory of functional differentiation' in transnationalism. According to this theory, 'space' would not be a given container in which social structure can develop; rather, 'space' would be an outcome of migration phenomena. However, Bommes thinks that the relevance of such a spatial category for the development of social structure in the frame of transnationalism is empirically still unproven. 
Instead of transnational social space, Glick Schiller et al. (1992: 1f.; see quote above) described the existence of the so-called 'transnational social field'. While the concept of a transnational social field remained poorly developed by Glick Schiller et al., it was later elaborated more precisely by Roudometof. Roudometof (2005) suggests that there are three different forms of transnational socialization: (1) 'transnational social spaces', which are interaction spaces based on the cross-border mobility and migration of people (as described, among others, by Pries); (2) 'transnational social fields', which refer to the rather formal relationships between institutions and organisations, but which do not necessarily include physical mobility across borders by the involved individuals; and (3) 'transnational communities' formed by migrants' social networks. A 'transnational social field' is the sum of the conditions for individual transnational action. Such conditions could be legal regulations (in particular concerning migration as well as work and residency permits), economic and sociocultural relations, or finally the individual involvement in transnational situations (e.g. binational partnerships, multilingualism, double citizenship). Given this definition, even non-migrants can potentially become part of a transnational social field (cf. Schmiz, 2011: 15). Physical mobility is no pre-condition for membership in and the ability to shape transnational social fields. In contrast, transnational social spaces have a more exclusive character. Membership in transnational social space calls for concrete, often face-to-face interaction with people in 'other' national contexts. Physically immobile people thus cannot become part of the transnational social spaces, but of course they can become involved in transnational social fields (Roudometof, 2005). Using this definition, Roudometof changes a bit the idea that Glick-Schiller et al. (1992) had about transnational social fields; it allows for a better distinction between the transnational social 'spaces' and the 'fields'.

Also, Mau et al. (2008) differentiate between a specific transnationalism that is based on migration and mobility and a more general transnationalism of the local and immobile people. The latter is sometimes to be understood as a consequence of the former, for example when migrants reshape the character of formerly autochthonous neighbourhoods in large cities (cf. e.g. Duyvendak's 'defensive localists' in his matrix on 'home-making strategies in a mobile world' as discussed in section 3.5). Here, Bürkner (2005) critically remarks that 'transnational social spaces' have something mystical because their fundaments have a largely cultural character and they widely neglect economic reasons for transnationalism. Transnational structures might also develop out of economic necessity, and they cannot only be understood as a cultural phenomenon.

Finally, historians might argue that transnationalism has existed since nations were constructed. Yet, I agree with Pries' position that the new qualities and quantities of transnational experience cause changes in reflection about the social self and the belonging amongst ever wider parts of (still rather) nationally organised societies. It is often supposed that the transnational experience of nearly all parts of the national societies leads to the emergence of more hybrid or multiple identities on the 
individual level (Walker, 2011). Therefore, the individual experience of transnationalism is an interesting field for sociological research. Here, transnational migrants might offer valuable insights based on their lived experience of cross-border mobility. To sum up, transnational migration research might provide interesting objects of analysis.

\subsubsection{Transnational Migration}

Studies dealing with transnational migration developed as their own field within the wider topic of transnationalism (Faist, 2000). The academic fields of sociology, cultural studies, anthropology, and geography developed a growing interest in transnational approaches to study new forms of migration because these no longer fit into the unidirectional and permanent pattern of 20th century labour migration (Pries, 1997). Schmiz (2011: $\left.14^{28}\right)$ comments: 'Since the 1980s, a large novelty in international migration research has been the focal shift from studying the migrant actors and their uni-directional or bi-directional changes in geographic location towards an understanding of migration as a continuous state of a person. The approach of transnational migration applies this understanding and emphasizes the repetitive and cyclical migration of people.' These new forms of migration are supposed to feed into the re-composition of the relation between geographic and social space. Transnational migration and its specific character of a back and forth mobility between different geographic spaces (such as nation-states, regions or cities) causes a break in the mutual exclusiveness of social and geographic space. Pries describes that the current geographic spaces host several independent social spaces (to be witnessed in multicultural society, in global cities, etc.). Today different social spaces are layered on top of each other within the same territory. In geographic terms, social spaces may extend to different poles. They become geographically multi-polar and thus intervene in formerly foreign territory. Even though they are not the only group, transnational migrants are suspected to be the main actors enhancing these processes.

Translated to the lifeworld of transnational migrants, Pries observes a transnationalisation of the social world, caused by the 'increasingly border-crossing references in the life of the people' (Pries, 2008: $7^{29}$ ). The sedentary life seems to lose influence; the importance of one individual local reference frame, and thus one local commu-

28 Translated by the author from the German text: 'Eine große Neuerung in der internationalen Migrationsforschung stellt die seit den 1980er Jahren erfolgte Abkehr von der Betrachtung der AkteurInnen und den von ihnen vollzogenen uni- bzw. bidirektionalen Ortswechseln hin zum Verständnis von Migration als dauerhaftem Zustand dar. Der Ansatz der transnationalen Migration greift dieses Verständnis auf und stellt die widerkehrende, zyklische Wanderung von Personen in den Vordergrund.'

29 Translated by the author from the German text: 'zunehmend grenzüberschreitenden Lebensbezüge der Menschen.' 
nity, as dominant among earlier generations, gives space to a more extended reference frame including several local communities in different countries. This plurality of life locales leads to problems for sociological studies as it evades traditional and place-bound concepts. Kalwa $\left(2010^{30}\right)$ observed this in her studies of Polish transnational migrants in Germany: 'The main property of circular migration is a specific simultaneity of two ways of existing for the migrants, who function 'here and there', and who experience different forms of discrimination as well as of (cultural or social) ascent. The migrants incorporate different (yet often similar) social roles in both of their places. These social roles become fundamental in the construction of the migrant's identity. The life in continuous circulation causes an existence in a difficult-to-grasp cultural space between two worlds. This space is a symbolic area in the frontier-land, which Zygmunt Bauman considers as space of potential success of those who autonomously define the frontiers within it. By definition, such frontiers are fluent and provisional (Bauman 2003). As a consequence the experience of these circular migrants can be characterized as something betwixt and between, just like a liminal state of uncertainty. This property of circular migration makes it difficult to comprehend such an experience in its totality and to describe it in complementary ways. It simply evades the power of precise categories and of immobile perspectives.' This quote highlights the necessity to overcome methodological nationalism in social sciences, at least for the study of such border-spanning mobilities as described in transnational migration. The traditional concepts and categories of migration research are no longer sufficient.

Based on a literature review in the field of transnational migration, Schmiz (2011: 17f.) describes the life of transnational migrants in their own transnational social spaces and the wider transnational social fields. Transnational migrants have several alternative strategies for social inclusion and assimilation, the two standard topics of traditional migration research. First, they can reject inclusion and assimilation in the destination country and alternatively focus on their transnational social space. Second, they can still try to assimilate in traditional terms in the destination country.

30 Translated by the author from the German text: 'Das kennzeichnende Merkmal der Pendelmigrationen ist eine spezifische Gleichzeitigkeit zweier Existenzweisen der Migrantinnen, die „hier und dort“ funktionierend sowohl verschiedene Formen der Diskriminierung als auch des (kulturellen oder sozialen) Aufstiegs erfahren und in beiden Räumen unterschiedliche (wenn auch scheinbar ähnliche) soziale Rollen erfüllen, die sich im Konstruktionsprozess ihrer Identität als Migrantinnen widerspiegeln. Das Leben im Pendel ist die Existenz in einem schwer zu fassenden Kulturraum zwischen zwei Welten. Er ist eine symbolische Zone zwischen den Grenzen (frontier-land), die Zygmunt Bauman als Raum des potenziellen Erfolgs derjenigen bezeichnet, die darin selber die Grenzen bestimmen, welche in diesem Raum per Definition fließend und provisorisch sind (Bauman 2003). In der Konsequenz hat die Erfahrung der Pendelmigrantinnen in sich etwas vom liminalen Schwebezustand des „weder noch“ (between and betwixt), was eine komplementäre Darstellung, das Begreifen der Gesamtheit der Erfahrung erschwert, die sich der Macht präziser Kategorien und unbeweglicher Perspektiven entzieht.' 
Third, they can opt for multiple and simultaneous forms of inclusion in different social spaces, namely the destination country as well as the transnational social spaces. Empirically, all of these forms have been observed.

\section{Transnational migration, language, and culture: Transculturality}

Linguists also dedicate attention to transnational migration. In the recently published Handbook of Multilingualism and Multilingual Communication, Monica Heller (2007) asks if we are currently witnessing the globalisation-based advent of wider multilingualism. With the growing importance of symbolic goods, languages become more important for economic production. At the same time, these products circulate in extensive ways across the globe. Heller argues that multilingualism becomes more important for everyone: 'It seems likely that fewer people are protected from these processes; more and more, we all have to deal with the multiplicity of material and symbolic resources, language(s) among them, as part of our daily lives' (Heller, 2007: 540). As a consequence, in her linguistic studies she observed tendencies to both reinforce monolingualism through a standardisation of language as well as counterstrategies of maintaining linguistic diversity. Heller is convinced that more studies at the intersection between linguistics and transnationalism are necessary in order to understand how people's mobility leads to the distribution of languages and multilingualism. She concludes (2007: 548): 'This is a historical moment of discursive shift, one in which the political economic conditions of the globalized new economy are intimately tied to new ways of using language, and new ways of understanding what language is, and how it is connected to social identity and social relations. Transnational multilingualism is a first sign, and a key site for discovering what those changes are all about.'

As Schmiz (2011) points out, language is considered an important tool in becoming included in any type of social space. Concerning transnational migration, it is suggested that bilingualism and multilingualism will increase and lead to different forms of language-based social positions. Different situations are possible here. Transnational migrants might remain excluded in one of the national contexts of their transnational social space, as they master one language better than the other. Second, they might be equally proficient in the relevant languages in their respective countries. And finally, they might also have difficulties with all languages, not having mother tongue level in any of 'their' languages. This would most probably be the case for second-generation migrants or people who have migrant parents.

The interest is not, however, limited to languages and linguistic systems. In the frame of transnationalism, cultural studies deal with the relatedness of migrants to nationally defined cultural systems. On the one hand, it becomes obvious that transnational migration puts the traditional concept of 'multiculturalism' into question, as it draws on rather traditional forms of permanent immigration and the existence of stable and homogeneous ethnic groups in national societies. Prato (2009: 16f.) remarks that transnational migration calls for a reconsideration of integration into cultural contexts: 'Contemporary policies of multiculturalism cannot therefore [the 
extending transnationalism] ignore the significance of the links established at the intersection between the local, the national and the global.' Here, Prato acknowledges that different geographic scales have an interrelated influence on cultural practices through transnational migration. While Prato still thinks that the concept of multiculturalism can be adapted to transnational migrants' realities, other scholars criticise the term for its implicit assumption that 'cultures' are distinguishable (Stock, 2010; Conti, 2010). Multiculturalism describes the co-existence of different cultures that have a certain geographic origin; they are linked to specific territories. As such, a multicultural society in any given country is composed of a native culture that 'tolerates' immigrated cultures. These immigrated cultures are presumed to be 'authentic' and unchanged, and to reflect the cultural situation of the country of origin (cf. Stock, 2010).

Yet, the situation that is caused by transnational migration is better understood as a transcultural instead of a multicultural one, because transnational migrants 'transgress' the boundaries of national cultures and re-compose them in new forms. For example, Hühn (2010) studied German pensioners who circulate between Spain and Germany. As a theoretical starting point she used Welsch's definition of 'transculturality' (Welsch, 2000), which she translated into the following aspects: first, the crossing of borders and thus the transgression of national culture is essential; second, the emergence and creation of some new cultural phenomenon must be observable; third, a transcultural phenomenon must be describable independently from national culture or as overarching national cultures (this fact includes the parallel existence of traditional national culture and new hybrid transculture); fourth, transcultural phenomena are those that can be linked back to national culture. Hühn (2010) empirically found these four aspects in the cultural practices of her transnational German pensioners. Thus, she conceives of transnational migrants as drivers of transculturalism.

Equally, Conti (2010) adds that the formerly rigid and static conceptualization of culture has become obsolete, as cultural studies meanwhile have shown that culture is mainly supported and continuously changed by individual persons. Contemporary culture does not exist independently from people. Based on the work of Clifford (1994), Conti describes that the individual person is culturally dynamic: an individual continuously incorporates new forms of cultural belonging through participating in ever-new 'collectives'. These collectives can have two characteristics, argues Conti, following an idea from Hansen (2009). First, they can be defined by destiny (gender, generation, place of birth, social position of the parents). Second, collectives can be defined by personal interest (hobby, place of residence, attitudes, profession). Hence, each individual is part of different collectives, and as such 'multi-collective' (Hansen, 2009). As Conti (2010: 180f.) recalls, Hansen thinks of culture as rooted in such collectives. According to Hansen, collective cultures emerge out of the basic necessity to reduce the environment's complexity and heterogeneity. In different geographic scales, people build different institutional frameworks that facilitate everyday inter- 
action through standardization and homogenisation. Standards, symbols and norms then guide interaction, and they form a collective culture. For Hansen, the most important scale here is the local one, because geographic proximity is supposed to enhance the frequency of interaction, and thus the value of setting up a collective culture. Translated into the life circumstances of transnational migrants, this means that they are part of different collectives in different places and countries, and as such they enact knowledge about different cultural systems. They know about the differences and they know how to navigate within this difference. As a consequence, they become both the bearer and the designer of these systems (cf. Conti, 2010).

Based on this theoretical reflection, Conti concludes that people transgress all types of cultural systems as they incorporate membership in different collectives. This is because the mixture of collectives is individual for each person. Thus, what might seem coherent on the individual level of the person is not congruent with a collective system anymore: 'Any interaction can thus be considered as 'transcultural' (Conti, 2010: 182 $2^{31}$ ). Consequently, transculturality is the rejection of the idea that cultural systems can be distinguished from each other, as they are interwoven through the individual persons' mixture of membership in collectives. Finally, Conti uses Balducci's (1990) metaphor of the 'global man' (essere umano planetario) to explain the difference between intercultural and transcultural settings. Balducci mentioned that all individuals on this planet are interdependent and exchange with each other in more or less direct and conscious ways. Therefore they should employ an inclusive state of mind. Conti (2010) uses Balducci's idea to define the transcultural setting in which two individuals acknowledge each other as individuals and try to include each other by creating a completely new culture of communication. By contrast, in intercultural settings two individuals perceive each other as representatives of 'other' homogenous and collective cultures, and they try to approach the culture of the other.

Transnational migration is thus conceptualised as a powerful driver of cultural change, leading to more hybrid, transgressive and individualised forms of culture. An interesting empirical observation in this context was reported by Toplak (2011), who studied a group of transnational migrants who are also professionally engaged with culture: Toplak looked at Slovenian artists who have migrated to Argentina. As a main result, she found that the transnational life experience translates into the artistic work (e.g. paintings) of the case study group. In particular, those Slovenian artists who frequently travelled between Slovenia and Argentina were drivers of the creation of a new mixed style of artistic production.

31 Translated by the author from the German text: 'Damit kann jede Interaktion als ,transkulturell' gesehen werden.' 


\section{Transnational migration and identity}

Whereas the spread of transcultural phenomena may be one aspect in defining belonging in a new way, there are several other aspects that add to belonging and identity (Samers, 2010: 276f.). Migrants' identity is also influenced by class, gender, race, generation, etc. While there is no space to go into detail here, I would like to highlight that transnational migrants are presumed to develop multiple and hybrid identities (cf. Schmiz, 2011; Pries, 2008). Glick Schiller et al. (1992) have observed this phenomenon of multiplicity in transnational migrants' identity. Glick Schiller et al. (1992: 11) found that social groups such as hometown associations are important anchors and reference frames for transnational identification: 'Within their complex web of social relations, transmigrants draw upon and create fluid and multiple identities grounded both in their society of origin and in the host societies. While some migrants identify more with one society than the other, the majority seem to maintain several identities that link them simultaneously to more than one nation.' This quote highlights that one could imagine transnational migrants as developing several simultaneous and different or also new hybrid forms of identity, which extend national identities. Equally, Kaiser (2011) understands transnational migrants as having different social roles in different places. This multiplicity brings along a redefinition of the main question concerning identity (Kaiser, 2011: 5432): 'The great problem which occurs here is no longer the durability and the modern question for 'Who am I?', but the post-modern question for 'Do I incorporate all social roles which might become relevant to my existence?' Multiple appropriation of space, polycentric place relations and transnationalism are phenomena, which must be thought of as linked to changing patterns of identity construction by actors in the light of contextual changes caused by globalization and pluralisation.'

Here, the notion of Heimat/home seems to persist as an anchor point of identity, and it will remain related to existing spatial scales such as the nation, the region and the city. Against the suggested argument of an increasing supranationalisation of identity, Schmiz (2011: 1933) says: 'This [her opponent's] position is based on the

32 Translated by the author from the German text: 'Das große Problem, das sich hier ergibt, ist nicht mehr die Dauerhaftigkeit und die modern Frage nach 'Wer bin ich?', sondern die postmoderne Frage: ,Habe ich alle Rollen im Repertoire, die von mir gefordert werden könnten?‘. Multiple Raumaneignung, Ortspolygamie und Transnationalismus sind somit Phänomene, die in Zusammenhang mit Veränderungen der Identitätskonstruktionen der Akteure unter den sich wandelnden Bedingungen der Globalisierung und Pluralisierung stehen können.'

33 Translated by the author from the German text: 'Dieser Ansicht liegt das Argument zugrunde, dass sich traditionelle nationale und regionale Modelle von Identität und Zugehörigkeit weder in einer globalen Weltgesellschaft noch in einem postmodernen immateriellen ,Raum der Ströme' auflösen, noch durch supranationale Gebilde wie die EUverdrängt werden. Vielmehr spielt die Heimat, die eng mit einer nationalen Identität zusammenhängt und auf eine vorgestellte Gemeinschaft rekurriert (vgl. Anderson 1996), weiterhin eine wichtige Rolle für TransmigrantInnen. Verflechtungsbeziehungen und Netzwerke 
argument that traditional national and regional models of identity and belonging will neither dissolve in a global world society nor in a post-modern and immaterial 'space of flows', and it will not be replaced by supranational constructs such as the EU. Rather, the notion of home, which is strongly linked to a national identity and to an imagined community (cf. Anderson 1996), will keep its important role for transmigrants. Relationships and networks between people on the local, regional, national, global and transnational scale will not replace each other. Rather, the forms of living together will increasingly be differentiated (cf. Pries 2005: 21).'

Transnational migrants are thus suspected to develop new hybrid forms of identification while also referring to existing categories. Here, Goeke (2004) makes the critique that transnationalism studies are often poorly linked to social theory. In particular, the question of how transnational migrants develop feelings of belonging to various places at the same time cannot be studied without using social theory. This includes the fact that identification patterns are difficult to assess. Goeke argues for a more precise use of the 'hybridity' concept as an analytical lens and not as an observable variable. He says (2004: 196): 'Cultural hybridity moves the axis of differentiation from an external division between self and other to an internal plurality of differences. This is why hybridity should be understood as an analytical tool but not as a mode of self-description, especially since it is often a nameless and hidden category.' In transnational social spaces, identification is not limited to the description of the 'self' and the 'other' in relation to a national framework. Transnational migrants have the possibility of defining and being defined as someone in between the national 'self' and 'other'. Goeke uses the illustrative image of the transnational migrant as a 'translator' (2004: 195): 'From an outside perspective, they might be labelled as 'hybrids'. They are continuously involved in processes of translation between the supposedly 'pure' elements.' This translation is mainly a reflection on one's personal 'impurity'. Studying Balkan migrants in Germany, Goeke found that migrants also take into account aspects of 'places' and 'professions' when they reflect on their personal transnational identity. While places seemed to lose their purity and specificity and thus become less opportune for identity patterns, jobs and professional environments were increasingly included in identity by these migrants. Goeke reports that transnational migrants actively compare two or more national reference frames that are available for identification, but they do not show loyalty to the existing collective identities. Rather they develop strongly individualised means of identification which provides them a certain freedom from national identity constraints and which is subjectively perceived as more reliable. The main anchor point here often becomes one’s own biography (cf. Goeke, 2004).

von Menschen auf lokaler, regionaler, nationaler, globaler und transnationaler Ebene werden sich nicht gegenseitig verdrängen oder ersetzen. Vielmehr wird es zu einer weiteren Ausdifferenzierung der Formen des Zusammenslebens von Menschen kommen (vgl. Pries 2005: 21).’ 
A specific biographical approach to transnational migrants' patterns of identification is provided by Apitzsch (2003) as well as by Lutz (2004). Apitzsch understands transnational social spaces as invisible structures of political, cultural and legal intersections that provide guidance to transnational migrants' biographies, and that form the context of life experience and perception. Apitzsch thus argues that it must be the empirical project of transnationalism research to uncover these invisible structures within migrants' biographies. 'Biography as place of transnational and transcultural space is the intersection of collective constitution and individual construction' (Apitzsch, 2003: 72; cited in Lutz, 2004: 211). Adding to this, Lutz acknowledges that Apitzsch's approach is helpful in addressing latent cognitive patterns in migrants' transnational life experience. However, Lutz prefers to think of 'biographies' as 'articulations' rather than 'places'. According to Lutz, place is an atemporal notion that does not include the historic dimension of biographies, which only become what they are over the course of time. Understanding 'transnational biographies' as 'articulations' allows one to respect the dynamic character of a biography. If one thinks of this articulation as the process of linking the subjective 'self' to the surrounding discourse, then one must acknowledge that during the course of a lifetime, a biography is a continuous sequence of disarticulation and rearticulation of certain discursive elements (Lutz, 2004: 212f.). Here, Lutz refers to the concept of articulation as introduced by Stuart Hall in the 1990s in his articles on 'cultural identity' (cf. Hall, 1996). Lutz explains that a transnational migrant's self-positioning (including elements of identity) is mirrored in biographical narration. Furthermore, this biographical narration is subject to change in accordance with a continuously reflected upon discursive environment in which the migrant is embedded. Thus, in order to study transnational identities it is essential to assess the logics behind biographic articulation and narration.

Scherke (2011) also points out that transnational migrants often identify with different scales at the same time. Based on a study amongst migrant children in Germany by Dannenbeck (2002), she recalls that these migrants often answered the question 'Where are you from?' with spatial categories that are not reflecting nationality. Rather regional and local references were provided. Furthermore, other nonspatial references were used by these migrants. For example, Gender and religion showed up as adding to spatial categories.

Another approach to studying hybridity in transnational identity is provided by Mecheril (2011). Mecheril says that affiliation (Zugehörigkeit) is the key to an understanding of hybrid identity. Zugehörigkeit/affiliation is generally composed of three components: Mitgliedschaft (membership), Wirksamkeit (effectiveness), and Verbundenheit (attachment). The first component, membership, is generated by the self-reference to and acceptance of others to be part of a certain group, whose members share a specific idea of what this group is about. A person will be considered a member of a certain context (e.g. a social group) if they feel that they themselves belong to it, and if others tell them that they belong there. Then there is 
the component of 'effectiveness', which describes how effective the affiliation can become in terms of permitting and prohibiting well defined activities and habitus to its members. Third, Verbundenheit/attachment describes the emotional belonging of a person to a context that they are part of. This includes moral convictions and obligations, the cognitive and practical familiarity with the context (Vertrautheit), and finally material aspects as well.

Whereas traditional patterns of affiliation could be labelled 'legitimate' as they represent situations in which all three components are congruent, transnational migration often leads to 'illegitimate' situations of hybrid belonging. Mecheril basically defines 'hybridity' as the transgression and rejection of binary distinctions. It refers to a state of mixture in which the supposedly irreconcilable is reconciled with something new (cf. Mecheril, 2011: 48). Here, transnational migrants represent a type of social actors who develop hybrid forms of identity which are composed of multiple forms of affiliation to several national contexts, and which transgress national identity and reject the binary distinction between being part of the nation and being a foreigner. Rather they might identify as both or even as something completely new, being in between and evading traditional national contexts of belonging.

\section{Transnational belonging and civic participation}

Samers (2010: 279-297) discusses in detail how transnational forms of belonging interrelate with citizenship and civic participation. Screening the existing literature on migration studies, Samers (2010: 280) explains that transnational belonging could be described as bi-focal and 'creolized', and as representing a double engagement 'in which migrants constantly think of the "here" and "there", often in contradictory ways'. This means that in extreme cases they might feel that they belong neither here nor there, or to belong equally here and there. In both cases there is continuous reflection on one's own position. Migration scholars are discussing how to understand this form of belonging. While some think of it as an antipode to traditional assimilation of migrants in the host country, others argue for a possible parallelity of both processes - the incorporation into transnational environments and into the host country's society. Thus, the national scale and the involved nation-states play an important role in defining the frame for belonging, e.g. through providing access to (double) rights to vote, to access social security schemes, to work, to reside etc.

Yet, belonging is mainly perceived on a local scale, in the urban environment, where everyday life takes place. Here, Samers draws back on Vertovec's discussion of the notions of 'trans-localism', 'trans-locality', 'trans-regionalism', or the transnational village (cf. also Vertovec, 2001), where the specific importance of the subnational scale in transnational migration is outlined. Also, Smith's (2001) concept of 'transnational urbanism' stresses the relevance of the urban scale, as most travel of transnational migrants takes place between specific cities in different countries, and not necessarily the country as a whole. Samers then remarks (2010: 286): 'We should expect migrants to have diverse transnational and other attachments (trans-local, 
trans-regional, etc.) within and across multiple territories. These attachments are likely to produce different forms of political participation.'

Thus, looking for the ways in which transnational migrants engage in the different territories to which they feel they belong also calls for a differentiated approach that includes the interference between geographic scales. Samers cites the work of Koopmans (2004) who pointed out that local civic participation is heavily dependent on nationally granted opportunity structures. While participation became easier through changes in the legislation of citizenship and naturalisation procedures, many countries still exclude migrants from central aspects of political life such as elections. According to Samers, the migration literature hints at different scales of migrants' political engagement. On the national scale, transnational migrants' engagement is often defined by a double orientation to the political context of the host and of the home country. Here, transnational migrants engage in the transfer of political culture and political tools. Furthermore, their engagement might aim at changing the policy of one of 'their' countries towards similar models found in their respective other countries. On the local scale, hometown associations are often cited as an example of transnational migrants' engagement for a specific local community in the home country. In the host country, municipal 'consultative committees' have been installed in recent years across European cities, in which migrants are asked for advice and for their needs when it comes to the provision of local public goods and services. Samers (2010: 296) concludes: 'Migrants negotiate these multi-scalar realities in the context of 'super-diversity', sometimes by rejecting the norms and practices of the country of immigration, sometimes by adopting them, and sometimes by constructing, navigating, or negotiating complex transnational (or diasporic) identities, which involve attachments to real or imagined 'homelands'. [...] Dual nationality, jus domicile, and multiple belonging do not overall seem to dissuade political participation in the country of immigration. Quite the contrary, it may stimulate political involvement as countries of origin and destination become tied by large overseas communities and intertwined cultural, political, social, and economic networks.' Finally, he underlines that national, regional and local political opportunity structures mainly define such migrant political participation. While many of these issues are still problematic in terms of migration between the EU and so-called 'third countries', migration within the EU could already be considered a showcase of 'post-nationalization' (Samers, 2010).

The specificity of the European Union

Studying retirement migration of transnational German pensioners in Spain, Kaiser (2011) points out that the European Union provides a specific framework for the development of transnational migration. In particular, the possibility for free movement of people has been extended over the last decades. The right to choose freely where to live and where to work was first granted to workers in the 1960s, and then it was later extended to self-employed people and entrepreneurs. Non-employed people such as pensioners and students were allowed to move to any other country in the European 
Union since the 1990s; and in the 2000s the last barriers were abolished with the introduction of the Union's citizenship. People who intended to stay for more than three months in a foreign country did not have to ask for a residency permit anymore; they could now simply register as a resident of a place abroad. Furthermore, other institutional contexts were also standardised in the European Union. The most important novelty was the introduction of the Euro as a common currency, but smaller changes also occurred in the banking sector (e.g. opening bank accounts abroad), income tax law, access to insurance and social security systems, or the possibility to buy property in a foreign country (cf. Kaiser, 2011: 104f.). Difficulties might still remain for transnational migrants, if e.g. social security schemes are not transferable to other countries or if compatibility is not established between two nation-states' systems (Kaiser, 2011: 54f.).

\section{The transnational family}

Körber (2011) studied how families change in the frame of transnational migration. She observed that social scientists (such as John Urry and Richard Sennett) perceive that the increasing labour-market-driven needs for mobility in the global capitalism lead to an erosion of kinship and family ties. According to this position, 'family' comes into existence by spending time together in one place. This includes face-toface interaction and relative immobility. If people become more mobile, they will increasingly be forced to break up with such family structures. Körber disagrees with such a point of view, as it reflects an essentialist concept of family that is rooted in 'methodological nationalism' (2011: 93). It suggests that family can only exist in geographically sedentary lifestyles.

In studying several transnational migrants' family ties, Körber and her research team found that family today works also as a type of 'imagined community', which is assisted in virtual ways, and which adds to physical co-presence. Families today are becoming more and more multilocal. In addition to their function as an economic unit, they also become mythological reference frames. They inherit nostalgia and kinship, which can be described as 'proximity at a distance'. Therefore, ICT development was a necessary condition as it allows for interaction and the maintenance of relations in virtual ways. Family today is nothing stable anymore. At a distance, family has to be reproduced every day. Here, Körber (2011) refers to Schier \& Jurczyk’s concept of 'family making' (Familie als Herstellungsleistung) (Schier \& Jurczyk, 2007). Family has to be thought of as a sequence of physical absence and presence, in which collective agreements no longer define the ways in which family comes into existence, but conflicting interests of the individual family members are negotiated against each other. Transnational migration thus allows for extending the range of opportunities for families and does not necessarily destroy them. At the same time, it also brings along new duties and expectations for the individual family members (e.g. expected submission of remittances).

Empirical studies in the field of transnational families have resulted in wellknown concepts such as the 'global care chain', the 'transnational parenting' or 
'long-distance mothering', which all stem from a focus on female labour migration in the sector of domestic and care work. Here, transnational migration mainly refers to the migration systems that exist between the Global South and the Global North, or between the European East and West. These migration systems are characterised by young women, often mothers, who emigrate to wealthier countries in order to take positions in private households, where both partners are working full-time. Thus, they have to leave their own children and parents back home, and care for children and elderly people in a foreign country. This means that in the context of transnational migration family is not a given aspect of life anymore. Rather, it has to be reproduced by managing the absence-presence divide, which comes with the increasing mobility.

\subsubsection{Transnational Entrepreneurship}

A growing interest in transnationalism can also be observed among economic geographers and regional economists who have found 'transnational entrepreneurship' to be an extensive phenomenon (Drori et al., 2009; Henn, 2012). Drori et al. (2009: 1001) suggest that transnational entrepreneurs could be defined as follows: 'We [...] define TEs [transnational entrepreneurs] as social actors who enact networks, ideas, information, and practices for the purpose of seeking business opportunities or maintaining businesses within dual social fields, which in turn force them to engage in varied strategies of action to promote their entrepreneurial activities.' It is remarkable how clearly this definition encompasses non-material aspects: ideas, information and practices. This observation points to the fact that transnational entrepreneurs are a type of business-makers who successfully exploit the resources that two or more distinct and territorially limited markets might provide. The competitive advantage of transnational entrepreneurs lies in the access to market relevant knowledge and information in two or more countries. Drori et al. mention (2009: 1002): 'By virtue of their unique geographical affiliations, they may be in a unique position to exploit opportunities either unobserved, or unavailable, to other entrepreneurs located in a single geographical location.'

Drori et al. (2009) also point out that transnational entrepreneurship has to be distinguished from international entrepreneurship. Unlike many international businesses, transnational entrepreneurs work in small-scale business units. Just like many local businesses, transnational entrepreneurs must grapple with local and national institutional constraints, while international business groups are far more powerful and thus able to shape the institutional context according to their needs. Yet, unlike local businesses, transnational ones can compare different institutional settings and try to derive a benefit from that situation.

Schmiz (2011) remarks that transnational entrepreneurship must be differentiated from immigrant or ethnic businesses that primarily operate in the destination coun- 
tries of migration. Transnational entrepreneurs use two or more countries and their cultural contexts in their business models, but this does not mean that both contexts are equally important parts of the business itself. Empirical studies have shown that highly-skilled transnational entrepreneurs often focus on markets in the host country, while low-skilled migrants instead tend to focus on home country markets (cf. Schmiz, 2011: 24). Drori et al. (2009) add that ethnic entrepreneurship is distinctive in the sense that ethnic entrepreneurs rely heavily on local resources in the context of the host country. Furthermore, their business environment is characterised by co-ethnicity. Either, most of their clients stem from their own ethnic group, or customers and business partners are ethnic fellows. Finally, ethnic entrepreneurship can be considered a counter strategy against the failings in traditional forms of assimilation. If immigrants do not feel able to become part of the native majority of the host society, engagement in ethnic businesses is an alternative for economic and social integration.

In contrast, transnational entrepreneurs supersede the constraints that arise from ethnic entrepreneurship and its limitations to one's own ethnic group. They engage independently in two or more countries, and while not necessarily rejecting the ethnic component, they also make use of other resources. As such, Drori et al. (2009) speak of a bi-national and non-assimilating group of migrants who engage in transnational entrepreneurship. This means that for transnational entrepreneurship the personal experience of migration is one of the key resources for business making. Therefore, transnational entrepreneurs also differ from international entrepreneurs, who do not necessarily have a migrant background. Furthermore, whereas international businesses often try to create standardization and harmonization, transnational entrepreneurs understand cultural and institutional differences between countries as resources to their advantage.

Also, Faist (2000) observed that there is a shift from ethnic businesses to transnational entrepreneurship. Using the empirical example of Turkish people in Germany, Faist conceptualises entrepreneurship of migrants as a three-step model. Immediately after arrival in the host country, these migrants mainly submitted remittances back to Turkey, which were used for both consumption and investment in small startups in Turkey. In a second step, Turkish migrants invested their accumulated financial capital in Germany, where they founded ethnic businesses - mainly in the field of private consumption (restaurants, grocery shops, craftsmanship, and travel agencies). In the third step, Turkish people now increasingly invest in businesses in which both the host and the home country are part of the business environment. Typical sectors here are textile production and distribution, which requires larger sums of start-up capital, or import-export businesses. In this transnational economic space, transnational migrants could exploit insider advantages that result from language skills, cultural knowledge and pluri-local business networks (which are often supported by family members and friends in both contexts).

Equally, Drori et al. (2009) explain that transnational entrepreneurs are characterised by the capacity to recognise their insertion in two distinct cultural contexts as 
an advantage. They make use of their symbolic and cultural capital, different knowledge and skills. Thereby, transnational entrepreneurs tend to apply cosmopolitan instead of ethnic cognitive models. Their social context is the transnational one, not any context bound to one specific group, yet they are able to realise and to respect local cultural specificity.

A particularly interesting aspect in transnational entrepreneurship consists in the interrelatedness of culture and business. According to Drori et al. (2009), culture has to be seen as something not static and given; rather the individual can influence, shape and change it. Transnational entrepreneurs are considered a group of business makers who have a strong capacity to analyse and exploit culture and cultural difference, while at the same time being able to shape culture according to their needs. In reference to Putz (2003), Drori et al. (2009: 1009) remark: 'TEs adopt diverse schemas of meaning and strategizing within varied symbolic orders "leading action in social practice, namely as a 'repertoire' which offers various options of how to act and to which agents can have reflexive access" (Putz, 2003, p. 557). Such an approach views TEs as agents who have to redraw the boundaries of their cultures in order to follow action paths and routines embedded in both practice and diverse symbolic orders.' The same accounts for market and social institutions in the host and home country of migration, which are simultaneously influencing transnational entrepreneurs' opportunities and being modified by transnational entrepreneurs. Here, Drori et al. (2009) highlight the role of social capital and its multiple embeddedness in local networks. This type of double social embeddedness provides security and access to resources, and as such, can be considered a guarantor of market power.

Another interesting input to the research on transnational entrepreneurs stems from economic geographer Sebastian Henn (2012), who studied Indian entrepreneurs in the diamond sector of Antwerp. Referring to cluster theory, Henn mentions that the study of cluster dynamics mostly focussed on internal and local structures. Only recently, new approaches include the external linkages of localised industrial clusters. However, these external linkages are still poorly studied and conceptualised. One attempt was made by Bathelt et al. (2004) who think of the local cluster as a frame for knowledge circulation among local cluster members. They term this internal knowledge flow the 'local buzz'. Additionally to the local buzz, there are so-called 'global pipelines' which link different clusters and lead external knowledge exchange.

Henn tries to shed light on this by using the transnational entrepreneurs in the diamond sector as an example of how these 'global pipelines' between local clusters might work. In his literature review, Henn (2012) emphasises the role of family ties in enabling and supporting transnational entrepreneurship. Furthermore, he stresses the role of both local and international business relations in emerging knowledgeintensive economies such as IT. For cluster development, the ability of transnational entrepreneurs to 'translate' between different contexts is mentioned as advantageous (Henn, 2012: 499). Henn summarises (2012: 504): 'As they are more or less simultaneously engaging at two or more different locations, TE are able to draw on a worldwide 
resource base. Research on the interface between TE and regional clusters so far has come to the conclusion that TE contribute to the evolution of global production networks, to a transfer of knowledge into existing clusters and to the forming of new clusters in their home regions. Put generally, TE have been found to be beneficial for the development of clusters both in their home and in their host country.'

The example of Indian diamond traders shows that the exploitation of the double knowledge about Indian consumer and European producer markets caused the success of Indian traders in the world market. Furthermore, they traded in a cosmopolitan way, not differentiating their business partners by ethnic groups. At the same time, they kept their knowledge within their own ethnic group for two reasons: the traditional Belgian and British diamond traders underestimated their new colleagues from India, and the Indian community was very reclusive. Hence, they became successful transnational entrepreneurs who were neither fully integrated in Antwerp, Belgium nor in Palanpur, India. They operated in their own transnational social space. Consequently, the Belgian diamond sector was confronted with increasing competition and lost dramatically in market power and size. This example shows that transnational entrepreneurship can have a strong influence on the local context, in both positive and negative ways.

Still, the main problem for transnational entrepreneurs is the relatively high cross-border moveability of production factors, such as financial capital or intermediary goods, while the movement of people - such as the entrepreneurs themselves - is often limited by the legal regulation of migration. Therefore, empirical studies found that double citizenship is a good indicator for transnational entrepreneurship (cf. Schmiz, 2011).

Drori et al. (2009: 1014) conclude: 'The phenomenon of TE implies a distinct opportunity structure which enables those immigrants who found and maintain businesses to benefit from "two worlds" as a crucial factor for survival, a way of "breaking out," and/or a method for providing competitive advantage.' Furthermore, they mention that research must take into account the specific character of transnational entrepreneurship: namely, that transnational entrepreneurs are social actors who reflexively operate in different social contexts, and who have to handle multilevel organizational insertion.

\subsubsection{Transnationalism and Cosmopolitanism}

A current question in studies of transnationalism is to what degree this growing transnational life experience affects the individual cosmopolitan attitudes of the people (Mau et al., 2008). The concept of 'cosmopolitanism' dates back to the work of classical sociologists such as Kant, Simmel and Schütz. They developed the character of a 'cosmopolitan stranger' who gets in contact with a locally rooted social community. This description led to the idea that there is an opposition of 'the cosmopolitan' 
and 'the local', as Ossewarde (2007: 372) describes: 'The cosmopolitan is flexible and mobile enough to move through localities and jobs while the local is rooted and fixed in neighbourhoods and workplaces'.

Cosmopolitanism is conceptualised as a state of mind, an attitude, which allows a person to detach from a local context and to critically distance themself from it. The cosmopolitan person knows different local contexts and is able to compare them. The locally rooted only knows his or her own and is thus unable to take the perspective of people from other local contexts. The cosmopolitan person lives in a more abstract world, relying on what Merton calls 'knowledge about' - a technical knowledge, which is applicable in different locales. On the contrary, the locally rooted uses 'knowledge of acquaintance' which only works in one's own local context (cf. Ossewarde, 2007).

This idea of cosmopolitanism goes along with a normative understanding about cosmopolitan attitudes. Kant's vision of the 'world citizen' and a 'global citizenship' is the base for normative conceptualisations of cosmopolitanism (cf. Beck, 2002). The cosmopolitan person - ideal typically - accepts that all people are part of one and the same humanity. Although every person might be socialised in a specific local culture, the cosmopolitan acknowledges this difference of origin while rejecting any judgments or prejudices. The culturally other is considered a human being with equal rights who deserves to be respected. As a consequence, this normative approach to cosmopolitanism argues for a world citizenship and questions the legitimacy of the nation-state.

In the current literature on cosmopolitanism, the global-local opposition is quoted. The general argument is that the ongoing 'transnationalisation' of the national societies leads to a split into a more open-minded and tolerant cosmopolitan group of global agents, on the one hand, and a closed and ethno-centrist group of locals, on the other hand. It is suggested that the winners of globalisation, mostly 'brain workers' employed in multinational corporations and international political bodies, form the cosmopolitan group, which is detached from the local context and problems (Duclos, 1999). This group partially retracts from local solidarity and engagement (Andreotti et al., 2010). In contrast, the losers of globalisation, mostly bluecollar workers in industrial companies, form the local narrow-minded part of society (Mau et al., 2008), which fear the dissolution of the stable frame of national reference.

Yet, other positions are based on the conception of 'glocalisation' (Roudometof, 2005), which stresses the simultaneity of becoming more global and cosmopolitan as well as remaining rooted locally. Here, cosmopolitan attitudes coexist with a national and local orientation within the reference system of a person. Depending on the thematic field, an individual might take a more cosmopolitan and inclusive position or a more exclusive and local standpoint. These positions only form two extremes, and the empirical reality is supposed to be situated on a continuum in between.

Pries (2008) is rather critical towards the cosmopolitan standpoint. He thinks of his transnationalism studies as something separate. According to Pries, cosmopolitanism is too closely linked to the normative idea of a world society, something that 
Rumford (2008) called the 'one-worldism'. In this position it is assumed that there will be one world society to which everyone feels a belonging, and in which every person is related in their consciousness with all other people in the world. For Pries, however, transnationalism deals with a non-holistic perspective. Transnational lifeworlds are only connecting selected places, and not the world as a whole.

\subsubsection{Synthesis: Transnationalism as an Approach to Study Routes}

In section 4.1, I offered an overview of some aspects that revolve around the topic of transnationalism. Transnationalism - as a scientific field of interest and conceptual framework for empirical study - provides some interesting ideas on how to grasp cross-border mobility between countries in the frame of global capitalism. With the political, economic, and technological innovations that have occurred in the last decades, the worldwide social organization has changed, too. Increasing interaction across national borders can be observed. The concept of transnationalism allows approaching these new forms of circularity and exchange between actors from different national contexts. Pries $(1997 ; 2008)$ showed how transnationalism adds to other forms of internationalised socialisation. Some of them might still be studied using methodological nationalism, which is basically understood as the superposition of geographic space (national territory and political sovereignty) and social space (national society and institutions). Others - such as transnational socialisation - must be conceptualised as driven by and driver of disintegration of geographic and social space.

I focused on the micro level, on the individual transnational migrant and their characterisation. Obviously there are other levels such as the meso and the macro level (cf. Faist, 2000). However, I deem this individual level as the most relevant to my study of mobile creative knowledge workers. I stressed that transnational migrants are understood as a new type of migrant who circulates between two or more countries. This form of migration includes that transnational migrants elude traditional approaches of integration and assimilation in a host country. Rather, they proactively pick from both countries what they need and what they like. It is impossible to lock them into 'national containers'; they create and operate in their own transnational social spaces, which are characterised as a situation 'in between' and with the maintenance of social ties in different countries. These ties are more stable and include more frequent interaction than was the case for traditional forms of unidirectional migration.

Transnational migration is supposed to support the development of transcultural phenomena and multilingual settings. It changes the way people identify. Increasingly, multiple and hybrid identities show up and confound the traditional idea that people are rooted in one national culture and society. This includes that 'society' itself becomes less rooted in one bordered nation-state. Furthermore, transnational 
migration literature points out that new questions around the issues of citizenship and civic engagement will arise. So far, national legal frameworks and regulation regimes are still exclusive when it comes to transnational migrants with a different citizenship. However such transnational migrants are increasingly part of all nationstates in the world. So, equal participation in public social life must be negotiated with them. They often feel that they belong to countries where they are not officially acknowledged as citizens with equal rights (e.g. voting, political activism). Furthermore, I have mentioned that the European Union represents a specific setting for transnational migration because the Citizenship of the European Union, as introduced in the Maastricht Treaty of 1992, grants additional mobility rights to the member states' nationals. Last but not least, changes are evident on the micro-sociological level of interpersonal relations. I presented the social unit of the family as an example of this phenomenon. Families increasingly work according to the idea of maintaining 'proximity at a distance', meaning that not all family members will continue to live in the same place. Families are becoming transnational, too. As such, they must be actively constructed across borders by their members.

I have also referred to the literature on the economic impact of transnational migration. Here, the figure of the transnational entrepreneur was presented. Clearly, not all transnational migrants become transnational entrepreneurs, but if they do so, they seem to be distinct from international or ethnic entrepreneurs. Transnational entrepreneurs 'translate' between different nationally influenced business environments and exploit their knowledge about these differences. This insider advantage provides an opportunity for transnational business models. Depending on the degree to which they share their knowledge with the local business communities in their countries, these stocks of transnational knowledge might become global pipelines of knowledge transfer, and as such helpful to regional economic development.

Finally, I briefly hinted at the ongoing debate about the role of transnational migration for the diffusion of cosmopolitan attitudes. Some scholars argue that increasing cross-border mobility and personal experiences of migration will enhance cosmopolitanism because migrants' experience of being foreigners causes cultural flexibility. Other more sceptical positions argue against such automatism. Here, the argument is that transnational migration only involves selected places and not the world as a whole.

Even though the transnationalism perspective allows for a better understanding of contemporary cross-border mobility, there are still open questions and criticism. Schmiz (2011) thinks that transnationalism research did not yet provide sufficient definitions of the 'transnational migrant'. It is unclear according to which criteria a migrant can be labelled 'transnational' or not. How should this be measured? Should one use the frequency of trips, or of other exchange activities? Which exchange activities are relevant? Are only economic activities relevant, or cultural and identity-based ones as well? Schmiz therefore calls for the elaboration of a taxonomy of transnationalism, including criteria which are based on empirical research. 
In addition, much empirical work focuses on one national group within one transnational social space without internal differentiation. Second, there is a strong focus on remittances and ethnic groups. Both approaches include the problem that analytic units (nation and ethnicity) are considered as naturally given. Schmiz argues that the analytic units should better be defined from case to case using relevant criteria (Schmiz, 2011: 35). Schmiz also criticises the idea of an opposition between assimilation and transnationalism. She would prefer to study this opposition empirically and assumes that there might be more coexistence between assimilation and transnational belonging. Additionally, transnationalism studies so far have not brought any results concerning the longevity of the phenomenon. She suggests conducting more long-term inter-generational studies to see how transnational settings evolve over time.

Kaiser (2011) adds that the role of family ties lacks sufficient empirical insight. So far, transnational migrants are often looked at as individual actors. Yet, much of their decision-making happens in the frame of discussions in the family. Are family ties then inhibiting or facilitating transnational migration?

Bommes (2002) critically examines transnationalism by referring to transnational social space as a main concept. According to him, it is mainly based on spatial references, which suggest geographic 'container spaces'. However, empirical studies have not been able to prove their real existence. Thus, the concept remained metaphoric. One answer could be Apitzsch's idea to understand transnational social space as rooted in personal biography (Lutz, 2004: 210ff.).

After reading through a large bulk of transnationalism literature, I had a two-fold impression. I found it positive that in all these texts the issue of geographic scale was mentioned. Then, I was astonished by how clearly transnationalism acknowledges the importance of the study of the everyday life of transnational actors - not only migrants - and the specific role of the local level within transnational life experience. Yet, the negative impression I had is that there is poor information on the concrete role of the local scale within the national scale. The importance of the local scale is mentioned often, but then it is not further specified. Furthermore, there is only little information on the individual perception, feelings, emotional and socio-psychological aspects that accompany the mobility of the transnational migrant. Also, the point of a possible interrelation between these cognitive aspects and the concrete action of transnational migrants has not been developed profoundly.

In light of this, I find the concept of transnationalism quite promising for the study of current cross-border mobility. Nevertheless, studies of this theme remain deeply rooted in the 'nation' and the national scale as reference categories. This is even more astonishing as transnationalism scholars often criticise methodological nationalism for its inappropriateness. As such, I share the some of Bommes' (2002) critical points. On the other hand, I must admit that so far I cannot answer the overall question of what transnationality would be without the nation: trans__ity? And what would it be, if it were more consequent in its focus on the local scale: probably translocality? 
I will therefore use section 4.2 to switch to another current debate, which provides just such a study of mobile everyday life on the local scale - namely research on multilocality.

\subsection{Multilocality ${ }^{34}$}

In one of the 2009 issues of the journal Informationen zur Raumentwicklung (Information on Spatial Development, Issue 1/2.2009), published by the German Bundesamt für Bauwesen und Raumordnung (The Federal Office for Building and Regional Planning), 'multilocality' was introduced as an analytical concept that can be located between the notions of (circular) spatial mobility and migration. Authors from Vienna (Weichhart), Bonn (Sturm, Meyer), Dortmund (Reuschke), Chemnitz (Huchler, Weiske), Munich (Schier, Zierold), Frankfurt/Oder (Petzold), Basel (Duchêne-Lacroix, Winkler), Zurich (Rolshoven), Sitten (Stock), and Berlin (Dienel) discuss 'multilocality' theoretically and then provide empirical evidence. It should be mentioned that these authors are also the founding partners of the German speaking Netzwerk Multilokalität (network multilocality), which is dedicated to further improvement of research in this field.

While transnationalism and cosmopolitanism deal with geographically distant and culturally different reference systems, multilocality is explicitly focused on a smaller geographic scale - the local one. Here, the local scale is supposed to be the most important one for the experience of the everyday life and the cognition of space (Weichhart, 1990; Weichhart, 2009). Thus, multilocality scholars analyse the combination of different locations in an individual's everyday life. Rolshoven defines (2006: 181'35; cited in Weichhart, 2009: 1): 'Multilocality means Vita activa in multiple places: the entire active everyday life takes place in diverse locations which are visited for more or less long periods and which are used in more or less functionally divided patterns'.

Much of multilocality research is based on Hägerstrand's 'action space model' (1970), which circumscribes the territory used for the daily activities as reachable by an individual from their own dwelling. Multilocality scholars look at ways of the spatial organisation of the everyday life in an alternative way to traditional migration and circular mobility (e.g. commuting). Migration - in its traditional understanding means the spatial relocation of one's own home, and accordingly, of the related action

34 I have also published parts of this section in the Italian peer-reviewed journal Sociologia urbana e rurale (cf. Nadler 2011b).

35 Translated by the author from the German text: 'Multilokalität bedeutet Vita activa an mehreren Orten: Der tätige Lebensalltag in seiner Gesamtheit verteilt sich auf verschiedene Orte, die in mehr oder weniger großen Zeiträumen aufgesucht und mit einer mehr oder weniger großen Funktionsteilung genutzt werden.' 
space from place A to place B. In contrast, commuting and daily spatial mobility are understood as the maintenance of the home in a stable location A and the flexible design of the daily action space around that location. Now multilocality is defined as something in between these two socio-spatial poles. The multilocal individual combines two homes in the different locations of A and B and seeks to profit from the amenities of both of these locations' daily action spaces (Weichhart, 2009).

The central question is then, how do people experience this everyday alternation between two distant places? Suggestions range from a positive evaluation of 'free movement' to the negative feeling of 'being forced' into this specific way of life (Rolshoven \& Winkler, 2009). On the one hand, circulating between two homes could have a deliberating effect on the multilocal person. It might give rise to multiple identities and social roles, help to raise personal profits, and be stimulating. On the other hand, some multilocals lead such a life because they 'need' to do so in economic terms. They often experience multilocality as an external constraint to their monolocal identity and orientation. Social disintegration and reintegration of the multilocal individual into local contexts are thus central topics in multilocality research (cf. Duchêne-Lacroix, 2009). The relationship between an individual's feeling of belonging and the actually frequented territories also represent a field of interest, which is studied by looking at the individual capacity to produce spatial relations by residing/Wohnen (cf. Stock, 2009).

\subsubsection{What Does 'Multilocality' Mean and Imply?}

For the theoretical discussion, four papers within this thematic issue of the journal are of major importance. First, there is Weichhart (2009), who introduces the topic in a very general way and provides an overview about the mutual positioning of 'multilocality' to 'migration' and ‘daily circulation'. Then, Rolshoven \& Winkler (2009) discuss the multilocality concept in the light of theory from cultural studies and social sciences. Third, Duchêne-Lacroix (2009) asks for the cognitive and emotional impacts of multilocality, especially when it comes to personal relationship between people. Finally, Stock (2009) explains his notion of Polytopizität as enriching the housing focused multilocality research.

\section{Multilocality in between migration and daily commuting}

In the daily routines, every person links their needs to specific activities. There are places which are made for sleeping and resting, there are places which are made for working, and there are other places which are made for pleasure, enjoyment, and leisure. However, these places are not necessarily located in the same geographic area. So, human activity is always composed of travel between different locations in order to best satisfy the everyday needs. Here, Weichhart (2009) understands multilocal acting as a strategy to increase the chances of the satisfaction of all everyday 
needs. Within a tolerable limit of transaction costs (such as travel, temporal and monetary efforts, etc.) people will opt for a combination of different places. Here, one could see a first difference from understandings of traditional circular spatial mobility. Everyday needs and life are not considered as constraining the daily action space. Rather everyday life is conceptualised as an element, which influences the combination and integration of several locations. It is more about giving a feeling of home to the act of travelling than limiting travelling within the daily geographic outreach from one single home base. Home and everyday life overcome a mono-centric locational orientation. As Weichhart (2009: $2^{36}$ ) indicates, historically, people have always been more or less multilocal: 'Thus, it would be an appropriate strategy for a person to locate in a spatial position in which they find the most advantageous combination of utility offers which optimally complement the subjective utility demands. These places, of course, are not numerous and not always available for a certain person. Hence, it is an alternative strategy to change between different places and to use their placespecific offers, which complement one another, in an alternating way. Such a strategy appears especially reasonable in environments characterized by scarce resources. 'To be on the move' was the optimal survival strategy for hunter-gatherer societies as well as for every kind of nomadism.'

Similar definitions are also wrapped into different terms. Steinbrink. uses the term 'translocality', which he defines as (2009: 90f. ${ }^{37}$; cited in Hühn et al., 2010a: 17): 'a social and economic unit's system to secure one's own life, whereby its members are not all located in the same place ('translocal household'). It includes the coordinated use of the material and immaterial resources which are provided at the different locations, as well as the balancing of strategic agency of all members in these different locations with the aim of securing long-term existence and satisfying the (individual and collective) needs'.

36 Translated by the author from the German text: 'Für einen Menschen wäre es deshalb eine angemessene Strategie, eine räumliche Position einzunehmen, an der er oder sie eine möglichst günstige Kombination an Nutzungsofferten vorfindet, welche die subjektiven Nutzungsansprüche optimal komplementieren. Solche Orte sind natürlich nicht eben häufig und einer bestimmten Person nicht jederzeit verfügbar. Eine alternative Strategie ist es deshalb, zwischen verschiedenen Orten zu changieren und deren einander ergänzende Standortofferten wechselweise in Anspruch zu nehmen. Eine solche Strategie erscheint vor allem vor dem Hintergrund spärlicher Ressourcen sinnvoll. 'To be on the move' war für Jäger- und Sammler-Gesellschaften sowie für jede Form des Nomadismus die optimale Überlebensstrategie.'

37 Translated by the author from the German text: 'Ein System der Lebensabsicherung einer sozialen und ökonomischen Einheit, deren Mitglieder sich nicht alle an demselben Ort aufhalten (,translokaler Haushalt'). Es umfasst die koordinierte Nutzung der an den verschiedenen Orten zur Verfügung stehenden materiellen und immateriellen Ressourcen sowie die Abstimmung des strategischen Handelns der an den verschiedenen Orten lebenden Mitglieder mit dem Ziel der (individuellen und kollektiven) Bedürfnisbefriedigung und der langfristigen Existenzsicherung.' 
Here, we can see that there is a utility-maximising orientation that serves as an explanatory factor for multilocal action. However, such multilocality is limited by human needs for rest and sleep. Fundamental, as Weichhart (2009) explains, is the fact that the human being, between two day times of activity, needs a place to stay and rest (sleep). This place is considered the home. The home has the character that it is often related to property or long-term usage rights (owning/renting a house/an apartment), and therefore it could be considered a counterpart to mobility and movement ${ }^{38}$. Rolshoven \& Winkler (2009: $101^{39}$ ) similarly state that in cultural studies and sociology, 'dwelling' and 'mobility' are not often enough combined because they are considered opposite poles: 'In western societies the home is the symbol as well as the expression of sedentariness. However, when you look at it closer, it does not stand for the actually realised practice of being sedentary but rather for the wish to stay: for the wish to locate oneself and to belong.'

Therefore, the logic of maximising the utility of a location (of the home/residence) for an individual's activities follows an 'everyday life-oriented logic' (alltagsweltliche Logik), which is guided by an individual's or household's perception of the opportunity structure with the goal of maximising utility. Weichhart's (2009) principal argument is that an individual's or a household's location predefines their daily action space ('reachable from home in daily rhythm circulation'; cf. Weichhart, 2009: $5^{40}$ ). Thus, it affects the utility of this location for the individual's socio-economic development (Lebens- und Verwirklichungschancen). This also indicates that there might be links between the decision to live (multi-)locally and an individual's or household's social mobility. However - and this is new about multilocality - this everyday life does not merely start from one place in the morning and end with return to the same place in the evening. Rather it 'takes place at different places', including rest and sleep.

According to Weichhart (2009), the industrial age represented the moment when people benefitted most from residing in a single location. The design of the modern city, after a large wave of urbanisation, with its public transport systems, the rising availability of individual car use, the industrial production facilities, the modern housing blocks, and the decentralised concepts of service provision led to maximised utility in relatively small action spaces. However, since global economic integration, governmental supranationalisation, the affordability of long-distance travel (e.g. low-

38 In the German language, real estate is called 'Immobilie'. Here, we could see the semantic opposition of home/house/dwelling and mobility.

39 Translated by the author from the German text: 'In den westlichen Gesellschaften ist das Haus sowohl Symbol (Inbegriff) als auch Emblem (Ausdruck) der Sesshaftigkeit. Genau gesehen steht es jedoch nicht für die realisierte eigentliche Praxis der Sesshaftigkeit, sondern vielmehr für den Bleibewunsch: für den Wunsch, sich zu verorten und ,dazu zu gehören'.'

40 Translated by the author from the German text: 'von der Wohnung aus durch tagesrhythmische Zirkulation erreichbar'. 
cost airlines, high-speed trains) and the possibilities of ICT developed dynamically in the second half of the 20th century. In geographical terms, the action spaces of people rapidly extended. Nonetheless, this extension is different from the medieval, pre-industrial forms of 'nomadism'. The post-industrial particularity of action space extensions is that the geographic range became much larger than it was before industrialisation. Due to transport and communication technology today, geographically distant places can be combined in the everyday lifeworld (Lebenswelt) in order to exploit the utility potential of both places. Rolshoven \& Winkler (2009) call this the emergence of 'mobile living practices', which can be evidenced statistically by increasing residential relocation, labour mobility, leisure mobility and finally a rising amount of secondary household maintenance in nearly all western countries. This form of combining two places in a geographic distance that cannot be surmounted in a daily commuting rhythm leads to multilocality.

Figure 4.1 illustrates how Weichhart conceptually situates 'multilocality' as part of spatial mobility between the circulation type of commuting and the notion of migration. Weichhart (2009: $6^{41}$ ) says: 'Spatial mobility is used to describe the various movements between the locations of human activity. Thereby, today it is mostly distinguished between migration and circulation. Migration means a permanent relocation of the residence; circulation all the daily rhythm and out-of-home activities which start from the home and lead back to this home at the end of the day (work, shopping, leisure activities etc.). Daily commuting would be an example of such circulation. However, a commuter who only comes back home at the weekend because they are forced to maintain a second home at their work's location already represents a case of multilocality.' Circulation here is mostly linked to what is explained as spatial mobility in the sense of transport geography (cf. Gather et al., 2008), in which a daily travel routine takes place (e.g. commuting).

Weichhart also stresses the differentiation according to dimensions such as 'time' (e.g. everyday movement vs. unique move with permanent intention) and 'residency' (daily action space from fixed single home vs. one-time relocation of a single home). Again, multilocality is situated 'in between', because it describes a spatial strategy of individuals and households, in which the home is no longer composed of one single location. Multilocality means living in several homes and cognitively living one's everyday life at geographically distant places at the same time.

41 Translated by the author from the German text: 'Räumliche Mobilität wird auf verschiedene Bewegungsvorgänge zwischen Standorten menschlicher Handlungen bezogen. Dabei unterscheidet man heute meist zwischen Migration und Zirkulation. Migration bezeichnet eine permanente Wohnsitzverlagerung, Zirkulation alle tagesrythmisch ablaufenden außerhäuslichen Aktivitäten, die von der Wohnung ausgehen und wieder zu ihr zurückführen (Arbeiten, Einkaufen, Freizeithandlungen etc.). Tagespendeln wäre also ein Beispiel für Zirkulation. Handelt es sich jedoch um einen Wochenendpendler, der am Arbeitsstandort mit Notwendigkeit eine eigene Unterkunft benötigt, dann liegt bereits ein Fall von Multilokalität vor.' 


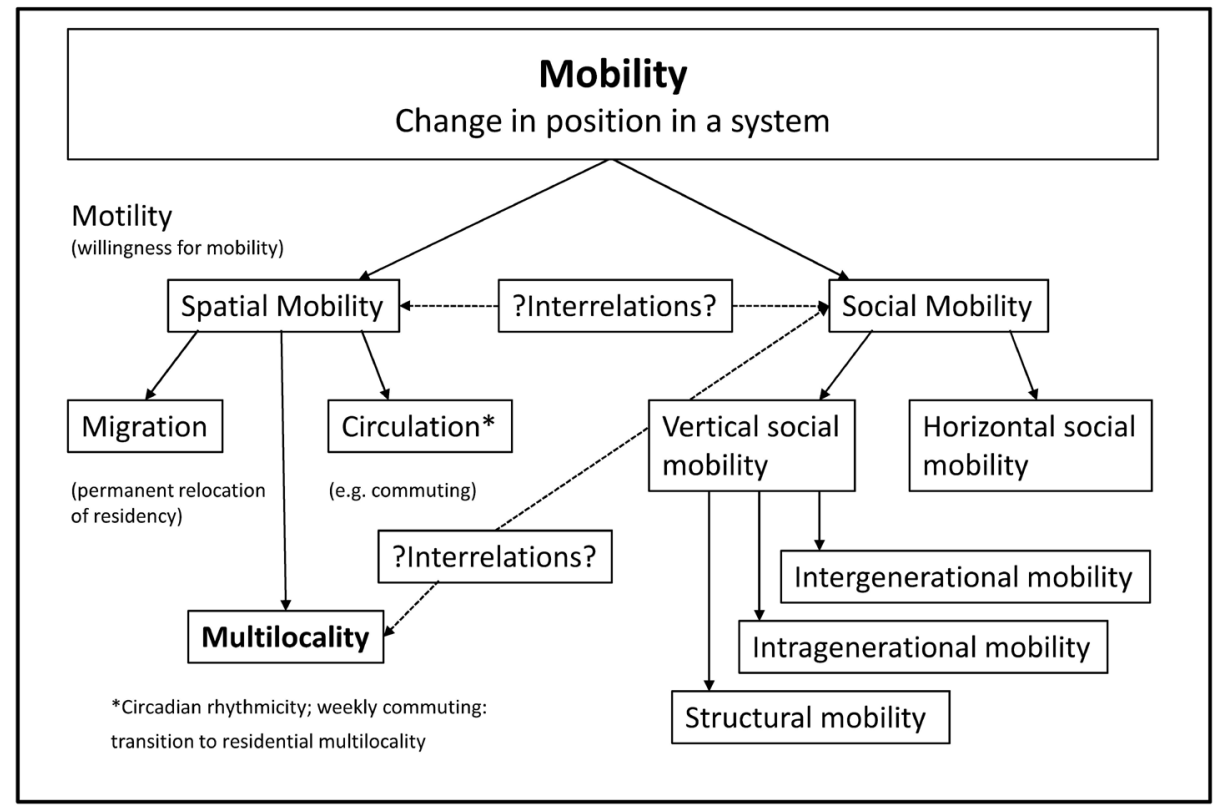

Figure 4.1: Terminological conventions of commuting and migration research; Source: Weichhart, 2009: 6; translated by the author in accordance with Peter Weichhart

Second, the concept of multilocality does not only challenge the 'single home' paradigm of the traditional spatial mobility approaches, it also questions the temporal dialectic between daily circulation and the long-term or even permanent move between locations. Multilocal individuals do not only refer to these two temporal dimensions when moving around between their different homes. Their stay could take only a single day, but also several months, or even years. Different from leisure or business tourists whose travel and stays at foreign places is related to extraordinary situations, for a multilocal person travel and different places are related to the 'everyday life'. So, 'everyday' infrastructure and services are fundamental within the multilocal life.

Weichhart (2009) notes that multilocality is considered by other scholars to be a particular subtype of migration: a status between migration and settlement. Yet, this understanding does not really reflect, as he says, the 'lifeworld-existential' (lebensweltlich-existenziellen) and 'cognitive-emotional' (kognitiv-emotionalen) sensual configurations of multilocality. Therefore, he prefers to understand 'multilocality' as being an independent social practice equal (gleichberechtigt) to migration and circulation.

Weichhart (2009) also draws on the action space concept (cf. Hägerstrand, 1970). As opposed to migrants or commuters, the multilocal individual achieves the combination of two or more complete action spaces. They can live an everyday life at two or more different places by operating from two or more homes. The commuter, however, can only partly live an everyday life in the different locations (in the one location 
where they work, in another where they have their leisure and private life). Migrants, in contrast, only live in one place, but use their knowledge from former places in their everyday life at the new location. Weichhart (2009: $\left.8^{42}\right)$ stresses the importance of two homes as a basis for the possibility of everyday life in multiple localities: '[Multilocality], however, is based on the availability of a second home in addition to the original or primary one, which can be used as an anchor point for everyday life at the second location.' Therefore, different locations connectively root a multilocal person's everyday life.

\section{Multilocality from a phenomenological perspective: multilocal lifeworlds}

Rolshoven \& Winkler (2009: 101f. ${ }^{43}$ ) do not speak of the connecting but rather the 'disconnecting' function of different locations. They prefer to stress the mobile character of multilocality instead of the rooting aspects. According to the authors, the multilocal practice of 'dislocating' equals a disconnecting of everyday life spheres: 'From the perspective of the moving person, mobility is a practice of dislocating, which disconnects different everyday life spheres from each other. The life takes place at different places - at home, while travelling, at the work or study place, at other places, where meetings take place, where everyday obligations are fulfilled or leisure time is spentbut still it remains one and the same life.'

It still seems unclear to what degree multilocal living could be characterised as the 'connecting' or 'disconnecting' of places and activities with or from each other. It is at least a practice of combining different locations within the everyday life sphere, and most probably it depends on the perspective one would take. Rolshoven \& Winkler (2009) approach multilocality from a cultural studies and phenomenological perspective. According to them, multilocality is a relational, actor-centred process, and as such the result of strategies and practices of everyday life and individual autopositioning (Selbstverortung) (2009: 9944): 'We could thus understand multilocality as a way of life according to Raymond Williams and his concept of culture as 'the whole way of life'.'

Dwelling is also a central term in Rolshoven \& Winkler's conceptualization of multilocality. They criticise social science for applying too static an understanding of

42 Translated by the author from the German text: '[Multilokalität] wiederum setzt voraus, dass neben der ursprünglich bestehenden Wohnung eine zweite Behausung verfügbar ist, die als Ankerpunkt des Alltagslebens an einem zweiten Ort genutzt werden kann.'

43 Translated by the author from the German text: 'Aus der Perspektive des sich Fortbewegenden ist Mobilität jedoch eine Praxis der Delokalisierung, die unterschiedliche Alltagssphären voneinander entkoppelt. Das Leben spielt sich an mehreren Orten ab - daheim, im Unterwegssein, am Arbeits- oder Ausbildungsort, an anderen Orten, an denen Begegnungen stattfinden, Alltagsbesorgungen unternommen oder Freizeiten verbracht werden - und es bleibt doch ein und dasselbe Leben.'

44 Translated by the author from the German text: 'Wir dürfen daher Multilokalität als Lebensweise im Sinne des von Raymond Williams formulierten Kulturbegriffs als the 'whole way of life' verstehen.' 
dwelling. For them, dwelling is instead a lifeworld (lebensweltliche) category, which leads to thinking of it as an activity. This activity is fundamental for understanding multilocal ways of life. Early indicators of specialised infrastructures for multilocals might be seen in the development of 'temporary housing' services offered at more and more places, providing attractive and flexible homes for medium-term stayers, with furnished apartments and domestic services.

However, Rolshoven \& Winkler (2009) recall that multilocality always has to be thought of as making mobility possible as well as forcing people into mobility. In describing the term 'network capital' as developed by Larsen et al. (2006), Rolshoven \& Winkler write (2009: 103f. ${ }^{45}$ ), 'Having to move could be an escape in all its various forms, just as having to stay could be called forced locating. [It is about] mobile surrogate-places, a kind of flying carpet for translocal people on which one often takes a seat voluntarily, but more and more often also involuntarily. [...] A growing flexibility of life spheres has emerged due to the structure of the modern lifeworld, which both forces as well as makes possible the distribution of actual living to different places.'

Such a multilocal life, with its communicative and cognitive links between different locations, could have a significant impact on those living it. One the one hand, it might foster individual action potential and the stabilisation of identity. On the other hand, it might have negative effects on the social networks of the individual; it might cause psychological tensions and a perceived cut from a person's localised roots (cf. Rolshoven \& winkler, 2009).

\section{Multilocality and personal ties}

Duchêne-Lacroix (2009) adds to Rolshoven \& Winkler's observations of emotional consequences and personal relations of multilocality. He derives his understanding of multilocality from a look at its cognitive aspects. First, he imagines current societies as mobile societies in which a person's individual places are becoming more and more fragmented and multiplied. He calls this process the Archipelisierung (archipelagoisation) of life. Caused by globalisation, European integration, economic liberalisation and transnational networking, life is taking place more and more on different 'islands' as well as across national borders. Thus, social life and society are no longer co-extensive with national political territories. This conceptualisation of border traversing shows similarities to the basic ideas of transnationalism (Pries, 2008), the post-national 'sociologies' of Urry (2000) or the refusal of 'methodological

45 Translated by the author from the German text: 'Sichbewegenmüssen kann Flucht in ihren vielfältigen Formen bedeuten, ebenso wie Sesshaftgemachtwerden Zwangsansiedlung heißen kann. [Es geht um] bewegliche Surrogat-Orte, um eine Art fliegende Teppiche für Translokale, auf die man sich häufig freiwillig, aber immer öfter unfreiwillig setzt. [...] Aus den Strukturen der modernen Lebenswelt resultiert eine wachsende Flexibilisierung der Lebensbereiche, die die Verteilung des Lebensvollzugs auf mehrere Orte zugleich erzwingt und ermöglicht.' 
nationalism' (Beck, 2007). Duchêne-Lacroix describes the constituting character of these islands as follows (2009: $88^{46}$ ): 'The belonging of the islands to the great whole consists certainly of observable habits (e.g. the frequency and duration of sojourn at, or the travel to and between certain places, or the number of visits) or of facts (such as property, locations of work and residency, etc.), but also of subjective elements (the feeling of belonging, intensity of the commitment, etc.).'

Duchêne-Lacroix asks himself if the particular empirical perspective of multilocality research has to focus on 'subjective' indicators, such as affective belonging, or on objective indicators, such as durations of sojourn. According to him, the subjective aspects are important to catch the cognitive and emotional dimensions of multilocal living. He conceptualises multilocality as a 'temporal parallelism of presence and absence' at the involved places. The physical presence on one of the 'islands' always includes the risk of disintegration at all other places (or islands). Thus, he suggests four dimensions of integration, which become effective at the place of presence and which compensate for the perception of disintegration at the other places.

First, there is a 'functional' dimension, which is mostly characterised by normatively ascribed roles of family members. Each individual has to fulfil functional expectations at the place of presence (e.g. child care, household maintenance, construction of family everyday life, etc.). Second, the 'social' dimension of integration is linked to expectations of loyalty towards a social group at the place of presence. This means that a person - especially in their professional life - is evaluated by other social group members such as colleagues according to their presence and commitment to the shared group/organization/place. Multilocal persons react to this localised social pressure by developing individual adaptation strategies (e.g. strategic presence mobility - strategische Anwesenheitsmobilität) in order to keep in touch with their local networks and to have access to local informal knowledge. This leads to the third 'cultural-cognitive' dimension. According to Duchêne-Lacroix (2009), this dimension is characterised by the continuous updating of specific information about the life in one place. This dimension is linked to the informational asymmetry and differing socio-professional relevance of the multiple places within a multilocal life. Each locus disposes of a specific set of informational value for the multilocal person. In one place, certain information might be professionally irrelevant, but it is very relevant for personal reasons. In other places, however, this information can be professionaly important. Then, some places are more relevant on the global scale and they are connected to ICT-supported, continuous infor-

46 Translated by the author from the German text: 'Die Zugehörigkeit der Inseln zum Ganzen entspricht gewiss beobachtbaren Gewohnheiten (z.B. Häufigkeit und Dauer der Aufenthalte oder Reisen in und zwischen den Orten oder die Anzahl der Besuche) oder Fakten (Eigentum, Lokalisierung der Arbeitsorte, der Wohnorte etc.), aber auch subjektive Elementen (Zugehörigkeitsgefühl, Intensität des Engagements etc.).' 
mational flows, while other places' information is only updated sequentially and through more traditional channels (e.g. newspapers or phone calls). The crucial point is that in order to be included in the different places one has to know what is going on there and which information is locally relevant. Fourth, there is an 'identitary' dimension to integration. Also for multilocal people, identity construction is based on long-term habits, appropriation and perpetuation of international and local roots. This is what Duchêne-Lacroix (2009: $95^{47}$ ) calls the 'stable point in a modern nomadic career'. Duchêne-Lacroix (2009) concludes that these four dimensions are more important for the organisation of everyday multilocal life than geographic distance. He says (2009: 95f. ${ }^{48}$ ): 'In spite of increasing multilocality, traditional expectations about presence remain important in the internationally distributed places. Caused by their sporadic absence, multilocal people are challenged to align a locationally dispersed life with the normality and implicitness of life at each of the involved places. This often does not work out. [...] Only if the presence achieves a certain intensity [not to be understood as duration of stay], it becomes possible for multilocal people to gain a foothold in a milieu, to appropriate a place, to tighten a position, etc.' Thus, multilocal living is also linked to the act of continuously switching between different and localised roles in order to cope with the expectations of the locally rooted others.

\section{Multilocality as Polytopizität}

Stock (2009) develops another approach to multilocality. For him the traditional conceptual opposition of dwelling/house/residence (as a place of being rooted and feeling familiar) and the mobility/mobile life is not sufficient for an understanding of multilocality. According to him, current sociological thinking - though it might refer to post-modern, transnational, cosmopolitan perspectives (e.g. Bauman's (2000) 'liquid modernity'; Castells' (2000b) 'spaces of flows'; Urry's (2000) 'mobile cultures') - still applies this traditional and dialectical opposition. Therefore, scholars today overestimate the 'uprooting' or 'disembedding' effect of the post-modern necessity to be mobile. He, similar to Rolshoven \& Winkler, distinguishes between multilocality research that is focused on the more narrow 'dwelling' aspect (maintenance

47 Translated by the author from the German text: 'stabilen Punkt in einer modernen nomadischen Karriere,

48 Translated by the author from the German text: 'Trotz zunehmender Multilokalität bleiben traditionelle Anwesenheitserwartungen an den international verstreuten Orten erhalten. Aufgrund ihrer sporadischen Abwesenheit sind Multilokale gefordert, ein örtlich verstreutes Leben mit der Normalität und Selbstverständlichkeit des Lebens an jedem der beteiligten Orte abzugleichen. Dies gelingt oft genug nicht. [...] Erst wenn ihre Präsenz eine gewisse Intensität [nicht Aufenthaltsdauer] erreicht, ist es für Multilokale möglich, in einem Milieu Fuß zu fassen, sich einen Ort anzueignen, eine Position zu festigen etc.' 
of multiple residences) and multilocality as a broader concept, which also includes everyday life practices and cognition.

Stock's term Polytopizität refers to a new conceptualisation of dwelling (Wohnen), which could be thought of as 'making geographies'. In accordance with Heidegger's idea of 'being on the earth', Stock includes every spatial aspect of everyday life into the term dwelling/Wohnen. In other words, it is about the 'capacity to produce relations to space' (2009: 108) ${ }^{49}$. As Stock believes, Heidegger was still much of a monotopical scholar. In Heidegger's analysis of rural places with small action spaces, multilocality did not exist. Consequently, Stock (2009) also bases his approach on action theory and the analysis of the lifeworld according to Werlen (1997). According to Werlen's approach, the social construction of space is not only limited to the question of how space is produced in the Lefebvrian sense, but one must also investigate the social practices of individuals to relate themselves and their everyday lives to different places. Wohnen (living/housing) is then to be understood as a social practice not 'in space' but 'with space'.

Stock (2009) develops three analytic dimensions for studying Polytopizität. First, wohnen/dwelling is always confronted with solving spatial problems. This problem solving process might be called Wohnpraktiken (dwelling practices). Second, 'spatial capital' (cf. Lévy, 2003) is always involved. This spatial capital is the capacity to surmount geographic as well as cultural and cognitive distance. Here, Stock (2009) uses the notion of Wohnregime (dwelling regime) for the description of this analytic focus. Third, wohnen/dwelling is also related to giving sense and symbolic value by practicing a certain life style. This is what Stock calls 'dwelling style' (Wohnstil). He summarises that, due to the ongoing functional differentiation of societies, the link between 'practice' and 'place' becomes more and more multiple, driven by the specific qualities of places for certain activities.

Stock (2009) distinguishes then monotopical (monotopische) from polytopical (polytopische) dwelling styles (Wohnstilen). Whereas familiar places are geographically located in proximity to the location of the dwelling in the monotopical dwelling style, the polytopical dwelling style is more complex. Here, familiar places (Eigenorte) are located in geographic distance to each other, while at the same time unknown or foreign places (Fremdorte) are also found in geographic proximity. Hence, Polytopizität is characterised by a differentiation of geographic and identitary/symbolic proximity, or as Stock (2009: 114 ${ }^{50}$ ) puts it: 'From a spatial perspective, mobile individuals should be considered 'geographically plural individuals'.'

Stock's 'geographically plural individual' - in contrast to monotopical people possesses particular capacities: (1) the capacity to construct place-based identities in

49 Translated by the author from the German text: 'Kompetenz der Herstellung räumlicher Bezüge' 50 Translated by the author from the German text: 'Mobile Individuen sind aus räumlicher Sicht als 'geographisch plurale Individuen' zu bezeichnen.' 
multilocal ways; (2) the capacity to transform unknown places into familiar situations via appropriation techniques; (3) the capacity to manage absence/presence; (4) the capacity to touch down in place or to settle only temporarily and periodically; (5) the capacity to manage a multilocal spatio-temporal orientation; (6) the capacity to interpret one place differently according to situational demands; (7) the capacity to relieve from local situations and to become independent from monolocal reliance.

This conceptualisation of polytopical lifestyles and geographically plural individuals enrich residency-centred approaches to multilocality research by not limiting definitions to residential questions. Wohnen/dwelling - in the narrow sense of a registered residence - might geographically and administratively take place at only one location, but it can still happen 'multilocally' in practice and through cognitive, emotional, symbolic and cultural perspectives of the lifeworld.

By referring to these four theoretical papers, I have demonstrated that multilocality is a concept which is primarily defined according to the objective criteria of (1) maintaining different residences (or dwellings) and switching between them with the possibility to (2) perform and organise the individual everyday life in each of these locations. However, multilocality is more than this objective definition. In addition to its central elements, 'multiple residency' and 'everyday life', it could also be considered a certain (3) lifestyle and, thus, a momentum of cultural distinction. Furthermore, (4) there are subjective and cognitive aspects of multilocality, which include integrative dimensions to compensate for the physical absence/presence duality. Finally, (5) multilocal living can be understood - if broadening the narrow approach based on dwelling/housing/residing (Wohnen) - as multilocal relationships between space and everyday practice.

\subsubsection{Connection to other Theoretical Frameworks}

The concept of multilocality is also linked to existing sociological frameworks. Weichhart (2009) briefly indicates how the concept of multilocality might be embedded into wider theory. The overall research interest in multilocality has to be seen as oriented on action theory (Weichhart, 2009: $12^{51}$ ): 'Multilocation is a process which - without any doubt - is based on the decision-making competencies of the individuals, and which is related to their capacity to become effective as a 'source of contingency' and to induce consequences of action in the social and physical world. [...] Social-geographic

51 Translated by the author from the German text: 'Multilokation ist ein Prozess, der zweifellos in die Entscheidungskompetenz der betroffenen Akteure fällt und auf deren Fähigkeit beruht, als,Quelle von Kontingenz' wirksam zu werden und Handlungsfolgen in der sozialen und materiellen Welt zu produzieren. [...] Vor dem Hintergrund der Ortsbezogenheit des Handelns bieten sich besonders sozialgeographische Varianten der Handlungstheorie an.' 
approaches of action theory seem to be especially appropriate from the perspective of the locational relatedness of every action.'

Weichhart (2009) also mentions ‘time geography', based on Hägerstrand (1970), as a possible theoretical reference for multilocality research. In particular, Hägerstrand's notion of 'constraints' might be helpful in order to understand the limiting effects of a dwelling's location on the multilocal individual's 'action space' and location benefits. Furthermore, the multilocal strategies to surmount these place-based limitations are an interesting field for research (Weichhart here speaks of Reichweitensysteme range systems; 2009: 12).

There have also been some recent innovations in the field of migration research that might be applicable to multilocality. The current debates about transnational migration, circular migration, social networking, and finally the new migration economy with its notion of 'subjective place utility' could be used. Last but not least, Weichhart mentions the vast theoretical framework that has been elaborated to explain 'social change'. Here, one might refer to the concept of 'liquid modernity' according to Bauman (2000), as well as to scholars of individualisation (e.g. Beck, 1992) and flexibilisation (e.g. Sennett, 2008). Furthermore, there is the cultural capital theory according to Bourdieu (1983), which could assist in a better understanding of the symbolic value of multilocal lifestyles and specific residential locations. Furthermore, Bourdieu's notion of 'capital' might be useful. Here, Weichhart (2009) points to Dirksmeier (2007), who has researched the 'residential capital' of certain housing locations.

\subsubsection{Empirical Evidence in Multilocality Research}

This section will provide an overview of empirical research that has been done so far in the German speaking countries, especially by the Netzwerk Multilokalität. Apart from understanding multilocality as a new perspective on empirical phenomena, the central question is what kind of evidence exists for empirically observable and new multilocal phenomena?

Sturm \& Meyer (2009) both work for the Bundesamt für Bauwesen und Raumordnung (Federal Office for Building and Regional Planning). This governmental institution maintains the largest database on housing and residential locations of people living on German territory. The data are continuously updated from the residential registry and the micro-census. Furthermore, a selection of large German city regions takes part in the registry of residents on the level of neighbourhoods. According to Sturm and Meyer, this is the best dataset - among the few existing ones - that could be used to estimate quantities and characteristics of the multilocal people in Germany. Technically, the calculation is based on the difference between registered people with a 'main residence' (Hauptwohnsitz) and the few ones with a registration based on a 'secondary residence' (Nebenwohnsitz). However, this is only an approxi- 
mation for the real number of multilocal arrangements as there are several measurement errors.

By analysing the registry data Sturm \& Meyer (2009) found that there are certain social groups in Germany who are over-represented in the secondary residence data: minors with divorced parents in different locations, students and professional trainees, professionals in certain economic sectors (such as media, politics, etc.) and elderly people with secondary residences in attractive countrysides. These groups mostly locate in inner-city neighbourhoods. The locations of the secondary residences tend to trickle into the outskirts in those cities where a secondary residence tax has to be paid.

Furthermore, the municipalities are confronted with different problems when planning their development. Multilocal persons are difficult to register, and it is still unclear to what degree they could be involved into the local community. Sturm \& Meyer (2009) suppose that the locally rooted opt much more for participation in civic engagement than multilocal people do. In times in which municipalities apply governance models that rely on civic participation, this might become a future problem. Rolshoven \& Winkler (2009), however, critically remark that such statistical data analysis, as done by Sturm \& Meyer (2009), could never cope with the complexity of multilocal everyday life arrangements, as they are only a brief static image of the real world. Furthermore, they think that in order to apply statistical methods, a technical definition of multilocality is needed. Such a universal definition, they say, does not exist so far. They refuse to apply quantitative approaches to multilocality research and rather suggest (Rolshoven \& Winkler, 2009: 10452): 'Perhaps an ethnographic exploratory approach is generally necessary for this topic.'

Dienel (2009) presents a case study on multilocal arrangements between central urban cores and peripheral rural regions, using the example of Berlin and the Baltic Sea island of Usedom. He develops his notion of Raumpartnerschaft (spatial partnership; cf. section 3.5), which might assist spatial planners in dealing with temporary inhabitants. He describes the spatial partnership as consisting of two opponent places which have a contrasting character. In his empirical examples, the urban cores (e.g. Berlin) are mostly the places of stable routines; the peripheral rural secondary homes are places for testing new behaviour (e.g. Isle of Usedom). Thus, multilocal living and secondary residencies might be a chance for social renovation and regeneration in declining rural areas. Spatial partnerships might have the complementary character, which could help to connect central growing cities and distant rural peripheries. The involved planning authorities should actively assist such spatial partnerships by identifying partner cities/regions and by providing appropriate infrastructural and service offers for the multilocal people (Dienel, 2004).

52 Translated by the author from the German text: 'Möglicherweise braucht es für dieses Thema grundsätzlich einen ethnografischen exploratorischen Einstieg.' 
Schier (2009) looks at the family level. She considers family as an everyday construction process - a 'family making' - and asks how this construction process is challenged by multilocal lifestyles. Due to the professional necessity for mobility and the increasing rates of divorces, families today live more and more as social networks in multiple households, which are frequently located in different places. Based on data from a study on family organisation, she explains that there are two basic types of multilocal families. First, there are those, which are characterised by mobile professionals who have to travel a lot. Here, the 'being together' or 'being far away' could not be planned and is very irregular (e.g. employees in the film industry). Second, there are families who are characterised by people who are working in another city during the week and who come back home at the weekend. This type is more regular and routinised, and family members could better anticipate the periods of physical co-presence. Both of these forms are to be understood as professionally induced multilocality. In contrast, Schier (2009) says, there is also family induced multilocality (e.g. by divorce, by generational division of the household, etc.).

Schier (2009) concludes from her observations that families are increasingly stressed by multilocal arrangements when it comes to spending life stages together, taking care of each other, or keeping physically and emotionally in touch. Today, the difficulty consists not only in finding time for the family but also in finding a common place to meet and to spend time with each other. The everyday organisation and constructing of family life is becoming more and more difficult. Geographically distant family life is characterised by an active process of 'family making'. Schier cites different innovative types of 'family making' (e.g. mobile families travelling together, planned forms of visiting each other, 'virtual family'), which lead to the question of the flexible and innovative design of the support infrastructure (child care, flexible schooling, municipal media points). She also points out that multilocal living is characterised by spontaneity. Planning the family life is becoming corrupted by unpredictable timetables for work, and thus for presence/absence.

Huchler et al. (2009) looked at the case of flight personnel. According to them, flight attendants are the prototype of a multilocal person, whose job already contains the dissolution of temporal and spatial barriers (Entgrenzung) to the point of crossing time zones. They asked how these aviation employees manage their everyday life between flying around the world and being home and caring for the family. They found that there are specific infrastructures provided by the airline companies in order to support their mobile employees. In addition, the flight personnel also rely on support from monolocal private acquaintances and family members. Huchler et al. (2009) point to the fact that multilocal living has significant disadvantages for the individual sphere. The maintenance of personal relations to loved ones becomes difficult, and professional necessities collide with demands from family members. Thus, multilocal living needs support systems that compensate for these disadvantages. Such compensation systems already exist in the aviation business. However, they have yet to be extended to other professional groups that have been confronted 
with multilocal living only recently. Nonetheless, Huchler et al. (2009) are rather pessimistic about the diffusion of appropriate compensation and support systems. According to them, the growth of low-cost carrier segments is more a sign of a decrease of support for multilocal flight attendants and pilots than a representation of a stable example of how to organise support for multilocal employees. Therefore, the extension of support systems to other mobile workers is hardly imaginable.

In her study, Reuschke (2009) combined mobile lifestyles and housing demand. She found that the flexibilisation of work environments and the pluralisation of job holding lead to an increasing importance of job-related commuting over a long distance. Reuschke questions the common understanding that multilocal persons distinguish between a 'primary private home' and a 'secondary professional residence'. She found that multilocal arrangements follow instead an alternating pattern in which people equally use different locations, not necessarily preferring one to the other. Therefore, the demand for the quality of the secondary home does not much differ from those of the primary home. The location choices are similarly complex for each of these several localities. However, Reuschke (2009) states that there is also a gender gap. Men apply the traditional type of multilocal arrangements, in which one can find a combination of a suburban or even rural primary residence and a secondary home in large urban areas. In contrast, women display 'modernised' multilocal behaviour, which is characterised by a combination of one urban pole with another urban pole. Reuschke concludes (2009: 4153): 'For lifestyle and mobility research based on the settlement-specific patterns of multilocal types of living, more detailed questions have resulted which ask about the everyday practice and mobility of 'complementary rurban lifestyles' on the one hand and multi-polar urban lifestyles on the other hand.' Similarly, Rolshoven \& Winkler (2009) point to a certain connection between multilocality and gender issues. They expect the extension of multilocal lifestyles to provide emancipatory potential for women, who - by switching between and combining different places - might overcome monolocal cultural restrictions on their personal development.

Weiske et al. (2009) try to develop a typology of multilocal actors. Based on a set of semi-structured interviews, they construct their typology along two dimensions in a matrix. First, there is the physical or spatial movement (in how many places do people actually live?). Second, there is the cognitive aspect of social mobility (in how many or at which places do people actually construct the 'sense' of their (multilocal) lives?). They found that their types are mainly differentiated by their degree of 'mental openness' towards their multilocal arrangements. As Rolshoven \& Winkler

53 Translated by the author from the German text: 'Aus den siedlungstrukturellen Mustern multilokaler Lebensformen ergeben sich damit für die Lebensstil- und Mobilitätsforschung vertiefende Fragestellungen nach der Alltagspraxis und Alltagsmobilität von ,komplementären rurbanen Lebensstilen“ einerseits und multipolar-urbanen Lebensstilen andererseits.' 
(2009) also mention, multilocality could be perceived as 'freedom' or as a 'constraint'. There is always an individual perception of one's own multilocality. The types described by Weiske et al. (2009) underline this idea empirically. They found that their types of multilocal households mostly aim at being only temporarily multilocal. Especially, biographical moments - at what moment in life multilocality is lived seem to be decisive for the openness towards and individual understanding of multilocality.

Hilti (2009) refers to the residential aspects of multilocality. Her understanding of multilocality is different from the one offered by Weiske et al. (2009) in that she does not so much focus on the perception but rather on the differentiation between 'multilocality' and 'multilocal housing'. Hilti defines (2009: 7854): 'Multilocal housing is a specific type of the multiple locating of people. [Multilocal housing] implies the existence and the use of more than one residence, or more generally: of more than one dwelling. [...] In contrast, multilocality as a wider term refers to the broader understanding of an everyday life multilocality, which has some overlapping with concepts such as daily-rhythm circulation, but which is also related to a more philosophical understanding, rejecting formal constraints. Multilocality, then, is [...] the active everyday life distributed to different places.'

She uses this distinction to be able to reconstruct the everyday lifeworld of her case studies of people commuting between Liechtenstein, Switzerland and Austria. According to her, the trespassing of administrative boundaries stresses people due to resulting bureaucratic issues. European administrative systems have not yet adapted to multilocal living. Thus, she says, multilocal housing in its official understanding (as two or more residences) no longer coincides with multilocality as a complex phenomenon (with all the existential problems in peoples' lifeworlds). This disintegration of lifeworld and bureaucratic definitions causes trouble, because in having to deal with two or more bureaucratic systems, multilocal individuals face several definitional inconsistencies. Practically, people who live multilocally use multilocal housing, but they cannot sufficiently be registered as multilocal residents as registration procedures are too old-fashioned to handle this growing phenomenon.

54 Translated by the author from the German text: 'Multilokales Wohnen ist eine spezifische Form der mehrfachen Verortung von Menschen. [Multilokales Wohnen] impliziert das Vorhandensein und die Nutzung von mehr als einem Wohnsitz, oder allgemeiner: mehr als einer Behausung. [...] Demgegenüber umfasst der Überbegriff Multilokalität ein weiteres Verständnis einer (alltäglichen) Mehrörtigkeit, welche zum einen Berührungspunkte mit Konzepten wie der tagesrhythmischen Zirkulation aufweist und zum anderen einer eher philosophischen Auffassung folgt, die auf formale Einschränkungen weitgehend verzichtet. Multilokalität ist dann [...] der auf mehrere Orte verteilte tätige Lebensalltag.' 


\subsubsection{Open Questions in Multilocality Research}

Weichhart (2009) points out that there are still a lot of open questions in the field of multilocality research. First, no one has ever quantified multilocality, which is partly due to its unfinished conceptualisation as well as weak data availability. However, it might be interesting to know how strong the phenomenon has become, and how multilocal groups are characterised with respect to socio-economic indicators. Second, he suggests that the multilocal actors are not a homogenous group. Rather one should investigate the different existing 'types' of multilocal individuals and their specific multilocal arrangements. Third, from a sociological perspective, multilocality could be interesting when it comes to asking how individuals switch between 'social positions', 'roles', and group participation when they change their location. Does multilocality, for example, facilitate multiple social identity construction? Fourth, there is the aspect of how families or households deal with multilocal arrangements from the logistic point of view. How do they weigh multilocal transaction costs against the benefits of multilocality?

Another focal point of further research might consist in the cognitive aspects of multilocality. When people switch between different places, what kind of character do these places have according to the individual's perception? Are places then characterised primarily according to their function? Or are there other aspects that are important for their characterisation?

Then there is the question of the impact of multilocal living on the places themselves: how does a large group of multilocal actors in a city or neighbourhood change its internal structure and systems? Here, one has to study the impact on the composition of local communities and the availability of multilocal people for local civic engagement. Furthermore, it might be interesting to have a look at processes of exclusion and gentrification on the level of neighbourhoods, which are induced by multilocal lifestyles.

Finally, the transition process between the multiple locations might be of interest. Multilocal people travel a lot, which translates into high temporal and financial costs. How do they perceive these passages of travel? What do people do in the times when they switch between places? These questions could be linked to the research by Watts \& Urry (2008), who are already working with 'mobile methods' in order to study how people use 'travelling time'.

\subsubsection{Synthesis: Multilocality as an Approach to Study Routes}

In my opinion, the multilocality concept offers a useful extension of perspectives on spatial mobility research. It systematically closes a definitional gap between the long-term character of migration and daily rhythm circulation. Given the differentiation of mobility types, the multilocal patterns are gaining importance. However, the 
first attempts to define multilocality and to distinguish it from other terms in mobility studies do not always lead to a satisfying result. The approaches presented in this literature review still lack a clear operationalisation of certain aspects of multilocal lifeworlds.

First, most of the scholars try to use an approach based on residential patterns to define multilocality (see e.g. Weichhart, 2009; Sturm \& Mayer, 2009). I believe that the orientation to define multilocality by the criterion of two or more households ignores the fact that multilocal arrangements in everyday practice are not necessarily characterised by multiple residency. Yet, they might more generally be circumscribed by everyday life taking place in different locations. Some of the scholars correctly imagine multilocality as a 'vita activa at many places'. Yet, in the end they limit themselves when it comes to operationalising the vast whole of such a 'vita activa' by only using the indicator of residential practices. This reflects only one detail of a person's everyday life.

The most convincing answers to this problem are provided by Rolshoven \& Winkler (2009) or by Stock (2009): they try to integrate the complexity of everyday life into the research on mobility with their approaches. They do not fear touching on 'difficult-to-understand' topics such as cognition, emotion, sense making or symbolic contents in relation to multilocal living. I think it is necessary to keep a definition of multilocality open to cases which are rather 'mentally multilocal' than actually being physically or even only residentially multilocal (cf. Stock's image of a 'geographically plural individual').

This leads to another problem of the presented approaches: they are still too much focused on physical travel in space. Clearly, a person who never surmounts geographic distance could less easily become a multilocally-minded person. The ancient philosopher St. Augustine of Hippo already observed: 'The world is a book, and those who do not travel read only one page.' However, an exclusive characterisation of multilocals as constantly travelling and switching between places does not support the intention to systematically analyse the various manifestations of multilocality. The virtual forms of multilocality are then at risk of being overlooked. Although being monolocal, in the sense of physical immobility, I think a person might have had a very mobile life in the past. In present time, this person could still be very mobile mentally, when e.g. keeping social networks alive, or combining different places cognitively within their everyday life.

Here one could refer to Larsen et al. (2006) and Urry (2000) who use the notions of 'imaginative' travel and virtual travel. According to these authors, imaginative travel is understood as the 'thought' or 'wished' movement to socially and/or geographically distant places, which is also an indicator of the capacity or open-mindedness to switch between and integrate locations into one's everyday life. According to Urry, imaginative travel is enhanced through mass media and the development of ICT. Today people can easily become informed about distant and foreign contexts without even travelling there physically. As Urry (2000: 69) puts it, imaginative travel is that 
dimension of travel 'by which distant events, personalities and happenings are mundanely brought into the living room and transform everyday life. As a consequence we imagine ourselves sharing events, experiences and personalities with many others, with whom we constitute certain kinds of community'. Urry thinks of the resulting community as a global one, and thus he contrasts with Anderson's 'imagined community', which is mainly rooted in the nation. Imaginative travel could then also feed into 'motility' - the general willingness and mental capacity to travel (cf. Gather et al., 2008; Kaufmann et al., 2004).

Virtual travel, however, is part of what Larsen et al. (2006) call the 'network capital' of an individual. Virtual travel sometimes substitutes physical travel; sometimes it also causes physical travel. However, it always enriches the network capital of a person in a mobile society, in which this type of capital increasingly becomes decisive for social inclusion. I reckon a definition of multilocality should be open to these types of 'non-physical' mobility, which are also important for the construction and practicing of multilocal arrangements.

Then, there is the temporal dimension of the presented multilocality approaches. Most of the scholars still stick too much to a periodical understanding of time in relation to multilocality. The length of sojourn or the frequency of absence/presence is still thought as a rather stable cycle. This, however, excludes several groups of mobile people from being multilocal according to such a definition. What happens with irregularly travelling business people? People who always travel, but who thereby locate in a more random and less predictable pattern according to business necessity? Are they multilocal or not? They do not necessarily return in periodic rhythms to the same locations. Yet, they are cognitively not monolocal. Or what about private travel, a person visiting a friend, and during this sojourn being hosted in the friend's house? The same might account for family visits. When do people become a multilocal in these cases? The length of the stay or the frequency of the visits are not really good criteria for distinguishing multilocality. Duchêne-Lacroix (2009) is quite right in pointing out that it is not about this periodic temporal understanding, but about the 'intensity' of the sojourn at a place. Here again, a focus on the emotional and cognitive aspects might be helpful for a better understanding of multilocality.

A rather secondary critical point concerning the current concept of multilocality is the strong focus on job and family as dominant reasons for multilocal behaviour. Associated with this is an image that places are functionally divided - in the sense that one place is related to family and the other to the professional sphere. However, in the end there might be a lot of other motivators for multilocal arrangements. Multilocality could also be thought of as being composed of a set of multifunctional places instead of a combination of monofunctional places. People do not always travel for only one reason. Different functions are often combined within one trip and as such within one place. This is an awareness that mobility researchers in the field of daily mobility/commuting have already achieved (cf. Gather et al., 2008). Multilocality researchers should also take this into consideration. When social complexity should 
be addressed in the study of multilocality, then simple causal models using monofunctional distinctions might not serve the ends.

Another issue is the construction of identity within the lifeworlds of multilocal people. Some scholars such as Stock (2009) or Rolshoven \& Winkler (2009) reflected about this, but there is more to it than the individual construction of self-perception, or of using multilocal living as a creator of a self-ascribed image. What about the notion of 'home' and belonging in residentially-focused multilocality? What role does home play? How are terms such as house, residence and home linked to each other? From a rather practical perspective, this means that multilocal people's conceptualisation of home has to be looked at. Does home in multilocal arrangements turn into something placeless and more related to social categories such as family, friends, networks, or even milieu?

This leads to a last weak point in current multilocality definitions. So far, not much has been said about how to integrate the cognitive aspect of spatial appropriation and orientation in space. Only Stock (2009) has remarked that there is a dichotomy between unknown, foreign places (Fremdorte) and familiar places (Eigenorte). But how should one imagine the current work of adaptation that multilocal people have to perform when switching between places? Nothing has been said about orientation as a part of adaptation. Multilocal people - if multilocality is not only understood as a repetition of the same trips - are confronted with the constant demand for orientation in new environments. How does this interfere with what Stock (2009) calls the 'capacities' to be multilocal? When people constantly have to leave familiar situations and adapt to new ones, do they develop behavioural patterns or routines for handling this highly stressful demand? And how do such multilocal routines lead to a change of our cities' physical structure and services? Will standardization of places in the sense of Duyvendak's 'generic places' be an outcome of increasing multilocality?

The definitions of multilocality are not yet complete, but they surely were not meant to be so. Multilocality is still an insufficiently defined concept. A common sense of what to integrate or not has not yet been achieved. Rather, the quoted approaches represent the ‘status quo' of multilocality research, which is still in its early stages. The Netzwerk Multilokalität has presented interesting theoretical approaches and empirical evidence that lead to the conclusion that this is a promising field of empirical research. There are a lot of interesting ways of looking at 'multilocality'. The variety of perspectives leaves open a vast research area for empirical and conceptual work.

Yet, the data availability from census and citizen registry is dissatisfactory, and a rigid technical operationalisation of multilocality - as necessary for quantitative analysis - does not match the informational ampleness that the phenomenon provides for social science. To summarise, I believe that the complexity of multilocality as a social phenomenon makes qualitative approaches more appropriate for multilocality studies. The multilocality concept thus provides an interesting (re-)new(-ed) field under the umbrella of both social and spatial mobility research. Empirical designs 
for multilocality research still have to be tested. Exploratory qualitative studies might serve to found a more substantial understanding of multilocality, and careful efforts of quantification might be helpful. In contrast, it seems still too early for large comparative and complex quantitative studies.

\subsection{Synthesis: Routes}

As I have shown in this chapter, 'transnationalism' and 'multilocality' provide two research topics that have intensively dealt with the increasing mobility between places. The interesting aspect in both of these approaches consists in the attempt to combine spatial mobility ('routes') and belonging ('roots'; cf. chapter 3). Obviously, there are some linkages between transnationalism and multilocality research. First, conceptual frameworks of both approaches refer to modernization theory, and in particular to the most recent approaches under the key words of 'second modernity’ (Beck \& Grande, 2010) or 'liquid modernity’ (Bauman, 2000). Both research programmes make use of the idea of an increasingly differentiating social reality, in which individualisation and global integration cause ever more complex patterns in social reality. This is often referred to with the linguistic metaphor that claims that social reality in the 'first modernity' could be grasped in 'either-or' (entweder oder) dialectics, whereas in the 'second modernity' it increasingly became a 'both-and' (sowohl als auch) continuum (Weichhart, 2010). Transnationalism as well as multilocality frame their main questions within this theoretical reference and also try to overcome its limitations.

Second, both concepts refer to perspectives that focus on the connections between the social and physical space of an individual. I have presented Ludger Pries $(2008$; 2009) as a reference for the idea that social and geographic space lose their formerly given superposition. Yet, there are a variety of other scholars (Faist, 2000; Glick Schiller, 2005; Steinbrink, 2009; Dienel, 2004; Dienel, 2009) who - independent of their background in transnationalism or multilocality research - have formulated and argued their conceptual approaches in a similar way: within one physical space more and more social spaces coexist and transcend each other, while at the same time individual social spaces increasingly exist across administrative borders.

Third, both fields agree on the observation that the everyday life of individual people and/or households is an interesting field of empirical study as it allows for the understanding of the complexity of 'transgression' phenomena from the viewpoint of the actors themselves. I do not want to negate the relevance of the meso and macro levels. Faist (2000) as well as Dienel $(2004,2009)$ have convincingly shown how individual border-crossing phenomena are reflected in processes of institutionalisation at higher levels, and how these meso- and macro-level structures influence the micro-level of the individual actor. However, I read both bodies of literature as an invitation to study the lifeworld of mobile persons. The interesting question is how 
mobile people relate to the resultant 'both-and' phenomena that seem so characteristic for their lives.

Fourth, both approaches not only deal with the combination of mobility and belonging, but they also focus on the parallel existence of different countries and places within the lifeworld of one person. A lot of research questions circulate around idea of multiple belonging to different territories, and these questions ask about the impact that multilocality has on place-based identification. In particular, the design and character of places that coexist in a person's life are still relatively unknown. Some scholars have explored this field of research and first insights have been discussed. Here again, we are approaching the issues we could find in section 3.5 about Duyvendak's types of belonging - in particular to generic places. Besides the idea of the 'generic places', the idea of the 'non-places' is mentioned in transnationalism studies as a possible type of place relatedness (cf. Kaiser, 2011: 53). 'Non-places' as a concept date back to Marc Augé (1995: 77f.) who says: 'If a place can be defined as relational, historical and concerned with identity, then a space which cannot be defined as relational, or historical, or concerned with identity will be a non-place.' In Augé's logic, 'places' always include a historic dimension in their present existence. According to Augé, the prototype of such a 'non-place' is the transit space that mobile people pass through while travelling, e.g. airports, train stations, highways, airplanes, trains, or ships. Augé's main argument is that through the time we spend in travelling, we increasingly pass through space instead of being in places. Thus, we perceive the time of transit as a rush through different landscapes that are chained like animals in a zoo, but we do not have contact with them. The time of travel is mostly spent in 'nonplaces', which are characterised by uniformity and the absence of history and organic social life.

Fifth, both approaches acknowledge the relevance of the local scale. While multilocality directly points to the local scale, the word 'transnationalism' instead suggests a focus on the national scale. However, looking at the results of transnationalism research, I found that the local scale is always considered the most perceivable or liveable for individual people. It can be experienced with the physiological senses (cf. section 3.2). Thus, transnationalism research reflects the national scale quite often through the lens of local everyday life experiences. The national, in contrast, is an abstract appearance. While it is already difficult to experience the local - let's say a city - in all its complexity and range, this is even more difficult for higher scales such as the national. Having said this, one also has to mention that multilocality research pays perhaps too little attention to the national scale.

The general suggestion of both these strands of the literature on mobile lives is that people today are less settled and rooted in stable, long-term, monolocal, mononational patterns than in earlier times. People are suspected to develop more dynamic and short-term patterns of rootedness and belonging. This includes the necessity to combine the local and the national (and sometimes even supranational or global) scale in one's own everyday life. Still, there is a majority of people who are 
immobile in the sense that they do not physically move across national borders or in that they do not live multilocally across administrative boundaries of municipalities. These people are orientated to geographical stability and long-term belonging, focusing on anchor points and orientating on their 'one' main place. Yet, their monolocal lifeworlds will be affected by global influences, too. These people might participate in more imaginative and virtual forms of mobility, even if they do not travel physically.

A still small but growing group of people interprets the arrival of the global/transnational in the local as an opportunity in life. These people rather opt for physical mobility. This mobility includes a broad variety of patterns that might be situated between the extreme poles of unidirectional long-term migration across borders, on the one hand, and the daily commuting rhythms between two places, on the other hand. Multilocality and transnational migration represent two mobility patterns somewhere in between these two poles. From a historian's perspective, they might have existed for a long time, but they have a new character and relevance in our contemporary societies.

Both perspectives share an interest in understanding the interplay between mobility and belonging. One could illustrate that transnationalism looks at the life of people from 'above' - from the national scale; and multilocality takes a look from 'below' - from the local scale. I imagine that most realities of people's lives actually happen in a field somewhere in between. As such, a combination of both perspectives might provide a more detailed understanding of current lifeworlds in the globalising societies.

So far, we have not dealt with the precise examination of terminology. Looking at the word stem of the terms at hand, we clearly find a reference to a geographic scale. Yet, there are a variety of prefixes (such as pluri-, multi-, trans-, or inter-) and suffixes (-ism, -ity, -isation), which are put in front of or behind the word stem. In both multilocality and transnationalism research, terminologies are not used based on a shared understanding and common definitions. For example, this is reflected in the open question: who is a transnational person, or who is a multilocal? There is no neat line to draw between inclusion and exclusion of cases in an empirical study. Additionally, there is the large problem of translating terms into other languages. I do not wish to go into detail here, as I do not deem it helpful at this point to elaborate a clear distinction between terminologies. Still, I agree with Oßenbrügge (2004: 1755; cited in Hühn et al., 2010a: 22), who says that for the study of trans-phenomena it is more important to operationalise 'what should be considered the entity for social integration'.

For the interested reader, a very helpful book is Transkulturalität, Transnationalität, Transstaatlichkeit, Translokalität by Hühn et al. (2010b). In this book, Hühn et al.

55 Translated by the author from the German text: 'was als Instanz sozialer Integration betrachtet werden soll'. 
(2010a) explain that from a linguistic perspective it could be formulated that (1) the prefix 'multi-' indicates 'many'; (2) the prefix 'pluri-' means 'several'; (3) the prefix 'inter-' refers to 'between'; and (4) the prefix 'trans-' means 'beyond' or 'moreover'. Furthermore, (5) the suffix '-ism' hints at an ideology and normative circumscription; (6) the suffix '-ity' describes a social fact or situation; and finally (7) the suffix '-isation' indicates a process. While this makes sense from a theoretical perspective, the practical use of terms in the literature is often less reflected. In his brilliant reflection on the use of terms in German-speaking academia, Petzold (2010) mentions that what he understands to be 'multilocality' is mainly labelled as translocality in the English speaking scientific community, as e.g. visible in the collection of papers on Translocal Geographies edited by Brickell \& Datta (2011b). Equally, Steinbrink (2009) uses the term 'Translokalität' in German, but Petzold (2010) prefers to differentiate between the two terms 'multilocality' and 'translocality'. He suggests understanding 'translocality' as a particular form of 'multilocality', in which a person develops emotional and social attachment to various places of the own lifeworld. As an antagonism, he would understand 'interlocality' as another form of 'multilocality', in which a person has one central place for attachment, whereas other places of the own lifeworld do not have a similar binding function. However, this definition of the prefixes contradicts Pries' (2009) argumentation about 'transnationalisation' and 'internationalisation'. According to Pries, the 'trans'-component is part of the 'inter'-term, while the 'inter'-term is also part of itself. Hühn et al. (2010a) cite the example of Welsch's use of the term 'multiculturalism', which they would rather call 'interculturalism'. Furthermore Hühn et al. (2010a) as well as Weichhart (2010) provide very helpful theoretical reflections on the denotative and connotative meanings of the various 'trans-'terms.

An interesting question remains: how does the arrival of globalism or transnationalism affect the attitudes of people towards other people and cultures from distant places in the local sphere of everyday life? The literature on cosmopolitanism remains divided about this issue. While there are authors that argue for a growing cosmopolitanisation of the world society, there are others who suggest a retreat into national and regional cultural spaces.

Furthermore, there is still more research necessary in order to understand how the local and national scale are linked in mobile lives. This includes the question for the development of supranational scales that might become relevant in people's lives. Pries' (2009) definition of supranationalisation allows first insights, but the European Union is theoretically the perfect empirical field for studying the supranationalisation of everyday life, because different processes of harmonization have been implemented here (e.g. the Bologna process in the field of education, the Schengen Agreement).

Finally, the issue of the corporeality of the human being was mentioned in transnationalism and multilocality research. It is discussed in relation to the problem that people cannot be equally physically present in all their places and countries in one given moment. In these two research agendas it is always about empirical situations 
in which absence and presence coexist. However, most studies only point to this issue and do not elaborate on it in more detail. Hence, there is a need to better look at how this contemporaneity of 'being here and not there' is included in individuals' lifeworlds.

I will conclude this chapter with the words of psychologist Dean Keith Simonton (1999: 207; as cited in Florida, 2002: 33) who said that, 'creativity is favoured by an intellect that has been enriched with diverse experiences and perspectives', and along these lines I think that the study of transnational multilocality is a fruitful endeavour for better understanding the role of place and mobility in creative knowledge workers' lifeworlds. 